\title{
Google Earth Engine for the Detection of Soiling on Photovoltaic Solar Panels in Arid Environments
}

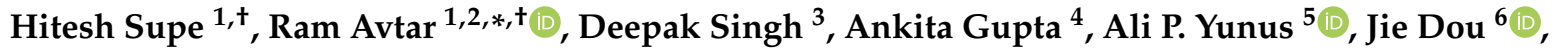 \\ Ankit A. Ravankar ${ }^{7}$ (D, Geetha Mohan ${ }^{8}$, Saroj Kumar Chapagain ${ }^{8}$, Vivek Sharma ${ }^{9}$, \\ Chander Kumar Singh ${ }^{10}$, Olga Tutubalina ${ }^{11}$ (D) and Ali Kharrazi 12,13,14 (D) \\ 1 Graduate School of Environmental Earth Science, Hokkaido University, Sapporo 060-0810, Japan; \\ hiteshsupe@gmail.com \\ 2 Faculty of Environmental Earth Science, Hokkaido University, Sapporo 060-0810, Japan \\ 3 Department of Geography and Resource Management, The Chinese University of Hong Kong, Sha Tin, \\ New Territories, Hong Kong, China; deepaksingh@cuhk.edu.hk \\ 4 Graduate School of Information Science and Technology, Hokkaido University, Sapporo 060-0814, Japan; \\ anki@m-icl.ist.hokudai.ac.jp \\ 5 State Key Laboratory of Geohazard Prevention and Geoenvironment Protection, \\ Chengdu University of Technology, Chengdu 610059, China; yunusp@csis.u-tokyo.ac.jp \\ 6 Department of Civil and Environmental Engineering, Nagaoka University of Technology, Nagaoka, \\ Niigata 940-2188, Japan; douj888@vos.nagaokaut.ac.jp \\ 7 Division of Human Mechanical Systems and Design, Faculty of Engineering, Hokkaido University, Sapporo, \\ Hokkaido 060-8628, Japan; ankit@eng.hokudai.ac.jp \\ 8 Institute for the Advanced Study of Sustainability, United Nations University (UNU-IAS), \\ Tokyo 150-8925, Japan; geetha.mohan@unu.edu (G.M.); saroj@unu.edu (S.K.C.) \\ 9 Rajasthan Renewable Energy Corporation Limited (RRECL), Jaipur 302001, Rajasthan, India; \\ vivek.rrec@gmail.com \\ 10 Department of Energy and Environment, TERI School of Advanced Studies, New Delhi 110070, India; \\ chander.singh@terisas.ac.in \\ 11 Faculty of Geography, Moscow State University, Leninskiye Gory, 119991 Moscow, Russia; olgatut@mail.ru \\ 12 Advanced Systems Analysis Group, International Institute for Applied Systems Analysis, Schlossplatz 1, \\ A-2361 Laxenburg, Austria; kharrazi@iiasa.ac.at \\ 13 CMCC Foundation-Euro-Mediterranean Center on Climate Change and Ca' Foscari University of Venice, \\ 30175 Venice, Italy \\ 14 Faculty of International Liberal Arts Global Studies Program, Akita International University, Yuwa City, \\ Akita 010-1292, Japan \\ * Correspondence: ram@ees.hokudai.ac.jp; Tel.: +81-011-706-2261 \\ + These authors contributed equally to this work.
}

Received: 13 April 2020; Accepted: 30 April 2020; Published: 5 May 2020

check for updates

\begin{abstract}
The soiling of solar panels from dry deposition affects the overall efficiency of power output from solar power plants. This study focuses on the detection and monitoring of sand deposition (wind-blown dust) on photovoltaic (PV) solar panels in arid regions using multitemporal remote sensing data. The study area is located in Bhadla solar park of Rajasthan, India which receives numerous sandstorms every year, carried by westerly and north-westerly winds. This study aims to use Google Earth Engine (GEE) in monitoring the soiling phenomenon on PV panels. Optical imageries archived in the GEE platform were processed for the generation of various sand indices such as the normalized differential sand index (NDSI), the ratio normalized differential soil index (RNDSI), and the dry bare soil index (DBSI). Land surface temperature (LST) derived from Landsat 8 thermal bands were also used to correlate with sand indices and to observe the pattern of sand accumulation in the target region. Additionally, high-resolution PlanetScope images were used to quantitatively validate the sand indices. Our study suggests that the use of freely available satellite data with semiautomated processing on GEE can be a useful alternative to manual methods. The developed method can provide
\end{abstract}


near real-time monitoring of soiling on PV panels cost-effectively. This study concludes that the DBSI method has a comparatively higher potential (89.6\% Accuracy, 0.77 Kappa) in the detection of sand deposition on PV panels as compared to other indices. The findings of this study can be useful to solar energy companies in the development of an operational plan for the cleaning of PV panels regularly.

Keywords: land surface temperature; normalized differential sand index; soiling of solar panels

\section{Introduction}

India holds a sixth of the world's population and its economic engine places it as the third-largest global carbon emitter [1,2]. Indian policymakers have developed the 'Intended Nationally Determined Contributions (INDC)' mechanism to reduce the country's carbon footprint. To this end, the National Solar Mission (NSM) is one such plan to fulfill India's INDC commitments. Under the NSM, India has a mammoth target of installing $100 \mathrm{GW}$ of solar photovoltaic (SPV) power [1,3], i.e., 60 Gigawatts (GW) in solar parks and $40 \mathrm{GW}$ in solar rooftop system (SRS) by the year 2022. The central public sector enterprise (PSE), Solar Energy Corporation of India Limited (SECI) and state renewable energy development organizations are responsible for the implementation of NSM targets at central and state levels as respective nodal agencies. Both SECI and state renewable energy development agencies coordinate to achieve the NSM targets. SECI also lays down conventions, frameworks and standard operating procedures for all kinds of solar projects in India. As of December 2019, the country has reached around $34 \mathrm{GW}$ of solar installations. Figure 1 illustrates the rapid increase in PV installation in India from 2010 to 2019 [4]. Looking at the overall numbers, the global solar panel installation witnessed exponential growth, with cumulative additions of more than $400 \mathrm{GW}$ of SPV based capacity from 2009 to 2019 [4,5]. In comparison to leading global SPV programs, Germany leads the race with more than $40 \mathrm{GW}$ of installed solar power capacity, which contributes to half of the country's electricity consumption $[6,7]$.

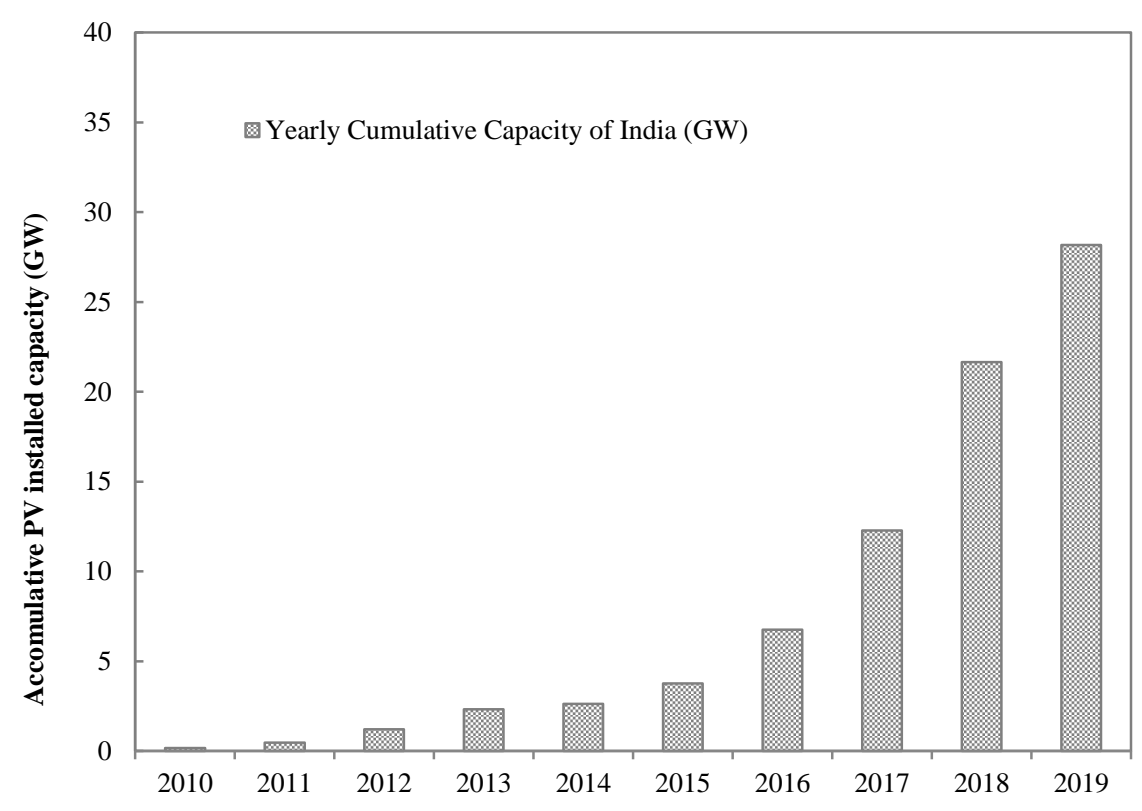

Figure 1. Time series plot of installed photovoltaic capacity of India from 2010 to 2019.

The global operational and value chain of the SPV industry is helping to resolve the challenges of decarbonization by diffusing solar technology. However, the solar panel system's power output efficiency generally depends on the design, environmental, and climatic factors such as orientation, 
sloping angle, shading, and weather conditions [8]. Two distinct challenges i.e., intermittence and soiling are dynamic. Intermittence is handled by forecasting and subsequent conventional generation-scheduling through automation at the macro and micro levels. Soiling on solar panels, specifically dust and sand, have been one of the most underestimated factors that significantly affect the performance of solar panels [8]. The deposition of sand particles on solar panels leads to temperature fluctuations, resulting in a slump in power generation $[9,10]$. It has been noticed that a soiled solar farm can significantly decrease revenue [11]. Several installed solar parks in India have already started facing this issue of solar panel soiling [12]. These challenges are accentuated in arid and dry regions, which are prone to dust storms and harsh weather conditions. To solve this issue, several entrepreneurial companies with a specialization in robotics, automation, and geospatial data have started working with different solar parks in India [12,13].

The challenge of soiled solar panels opens a new research frontier to explore the timing and intensity for the cleaning of solar panels. Looking at the technical operations, Saidan and colleagues [14] revealed that due to soiling in desert areas, the efficiency of SPV can drop up to $18 \%$. In one case study, researchers observed that the power output of SPV in the Riyadh region of Saudi Arabia was drastically reduced by up to $32 \%$ in about eight months [15]. This is because the high and continuous wind in the plain desert field leads to the formation of a sand layer on the PV panel surfaces [11]. Eventually, this drops the intensity of incident sunlight and blocks the electromagnetic waves of some specific wavelengths. As a result, both electric current (I) and voltage (V) drops, subsequently reducing power generation [16]. A study of sand deposition and its impact on the solar panel performance by Jiang et al. [17] revealed that only $22 \mathrm{gm} / \mathrm{m}^{2}$ of dust deposition can reduce the SPV panel efficiency by $26 \%$. A study conducted by Yap et al. [8] near Casuarina, Northern Territory, concluded that during the dry season, dust accumulation is one of the primary factors behind the system's poor efficiency-leading to a reduction of $19.6 \%$ and $9.2 \%$ of the maximum energy output [8].

The output of an SPV system can be increased by removing the dust layer via conventional cleaning methods such as water-based cleaning, which is the most extensively used method [18]. A study conducted by India's Council of Energy, Environment and Water (CEEW), has estimated the water requirements for weekly cleaning cycles of solar plants in the country ranges between 7000 and 20,000 liters per MW per wash [19]. Furthermore, cleaning with water is both labor-intensive and carries the risk of physical damages due to human error. The scarcity of water in arid and desert regions adds another challenging dimension and for a water-stressed country like India, this overlaps with the sustainability challenges of livelihoods and agricultural priorities [20].

As of March 2020, Bhadla is one of the world's largest solar parks with $2245 \mathrm{MW}$ capacity. It is located in the Thar Desert of Rajasthan, India, and brings some operational challenges vis-a-vis the terrain and the landscape. The gusty winds with soil erosion at the rate of $7.67 \mathrm{~g} / \mathrm{m}^{2} /$ day can pose a serious threat to the installed solar farms [18]. Three days of soiling effects are capable of dropping the solar farm's efficiency by one-fourth of its original capacity $[19,20]$. This makes the cleaning of solar panels the inevitable option for the plant operators. Water cleaning is the most common option, but the shortage of water resources in Rajasthan state handicaps the conventional cleaning methods. Furthermore, the water diversion canals built for the cleaning of solar panels in Bhadla have drawn criticism from the farmers and other environmental activists and groups. Due to the severe water scarcity issues in this region of India, the huge quantum of water cannot be guaranteed for cleaning purposes. Furthermore, any future water supplies will have to adhere to the dynamics of a tariff structure to avoid 'the tragedy of the commons' [21]. This can lead to tariff precariousness in some parts of India, where water tariff rates have been hiked 100 times for industries [22]. A similar escalation in water tariffs in Bhadla can drastically influence the economics of solar plant operations.

The limits of water as a cleaning agent for solar panels call for the search of a water-efficient or water-free cleaning mechanism aided by image-based surveillance tools collected from drones and satellites. This will require the identification of dust and soil spots on panels with precision and accuracy. It can help in both scheduling and optimization of panel cleaning inventories across the vast 
tracts of solar parks. In this context, the use of drones helps collect images of inaccessible areas with high-resolution data. A few studies have used photographic imagery to detect sand deposition on panels by using drones [8]. In the absence of drone technology, the satellite remote sensing techniques have been widely used in a variety of fields like the monitoring of soil types, geomorphology, land use/land cover, and the monitoring of rice crops [23,24]. Recently, with improved radiometric performance and higher spatial and temporal resolutions, satellite images have become indispensable tools in a variety of fields. Several studies discuss the use of satellite images in detecting and extracting soil information [25-27]. Such methods can be further applied to solar farms to detect the deposition of sediments on the panels. However, there are no specific satellite-based indices to monitor soiling on solar PV.

Robotic panel cleaning can reduce the manual and water costs. However, the excessive use of robots can affect the panel's lifespan. It can potentially add to more secondary capital costs (with the replacement of damaged panels) and deplete the profit margins. This requires robotics arm cleaning to be supervised with the exact location of dust and dirt markups on the panels. It can further help in efficiently scheduling the cleanup of the panels. The purpose of this study is to introduce the application of the Google Earth Engine (GEE) in monitoring the soiling of solar panels. In this study, we explored various soil and sand-based indices using various satellite data to monitor soiling in PV panels. The GEE is an open-source platform with great potential in expanding the research frontiers. The GEE has also been used in various applications such as monitoring of rice extent, cropping patterns, and growth stages [28]. Archived Landsat 8 and Sentinel-2 images from September 2017 to February 2019 are used in the GEE for the analysis. The approach used in this study is a combination of data retrieval, image processing, outcome analysis, and visual interpretation. The periods with a high amount of sand deposition can be determined through satellite image analysis, which can further help to optimize the use of water and self-cleaning robots.

\section{Study Area}

The state of Rajasthan, India has a vast unused, barren, and affordable land that has solar irradiation of $5.72 \mathrm{kWh} / \mathrm{m}^{2} /$ day, the highest in the country, and thus making it a very suitable site for solar park development [29]. Rajasthan has about 20 million ha $\left(208,110 \mathrm{~km}^{2}\right)$ of desert land, which is $60 \%$ of its total geographical area of $342,300 \mathrm{~km}^{2}$ [30,31]. Moreover, this area receives scanty rainfall, hence good sunshine is available throughout the year [30]. The study area focuses on Bhadla solar park in the Jodhpur district of Rajasthan, India, as shown in Figure 2. This solar park is a $2.25 \mathrm{GW}$ project located at $27.5015 \mathrm{~N}$ latitude and $71.9358 \mathrm{E}$ longitude, approximately $220 \mathrm{~km}$ away from Jodhpur headquarters on the Bap-Bhadla road, as displayed in Figure 2. For the development and operations of Bhadla Solar Park, the central PSE-SECI is coordinating with its state-level counterpart-Rajasthan Renewable Energy Corporation Limited (RRECL). The project construction was started in July 2015, spanning a total area of 5,783 ha [29]. About 10,000 ha of government-owned land has been allocated for this solar park development. Figure 2 highlights four sections of the Bhadla solar park (P1, P2, P3, and P4 marked with red boundaries) which are considered for this study. Different sections and phases of these plants are owned by various public and private sector companies acquired through bidding and auctions. SECI, RRECL, Power Grid Corporation of India Ltd. (PGCIL), state power generation, transmission and distribution companies along with the park developers are the key stakeholders in the Bhadla Solar Project. SECI through RRECL coordinates with all the stakeholders for the development and operations of this solar park [32]. 

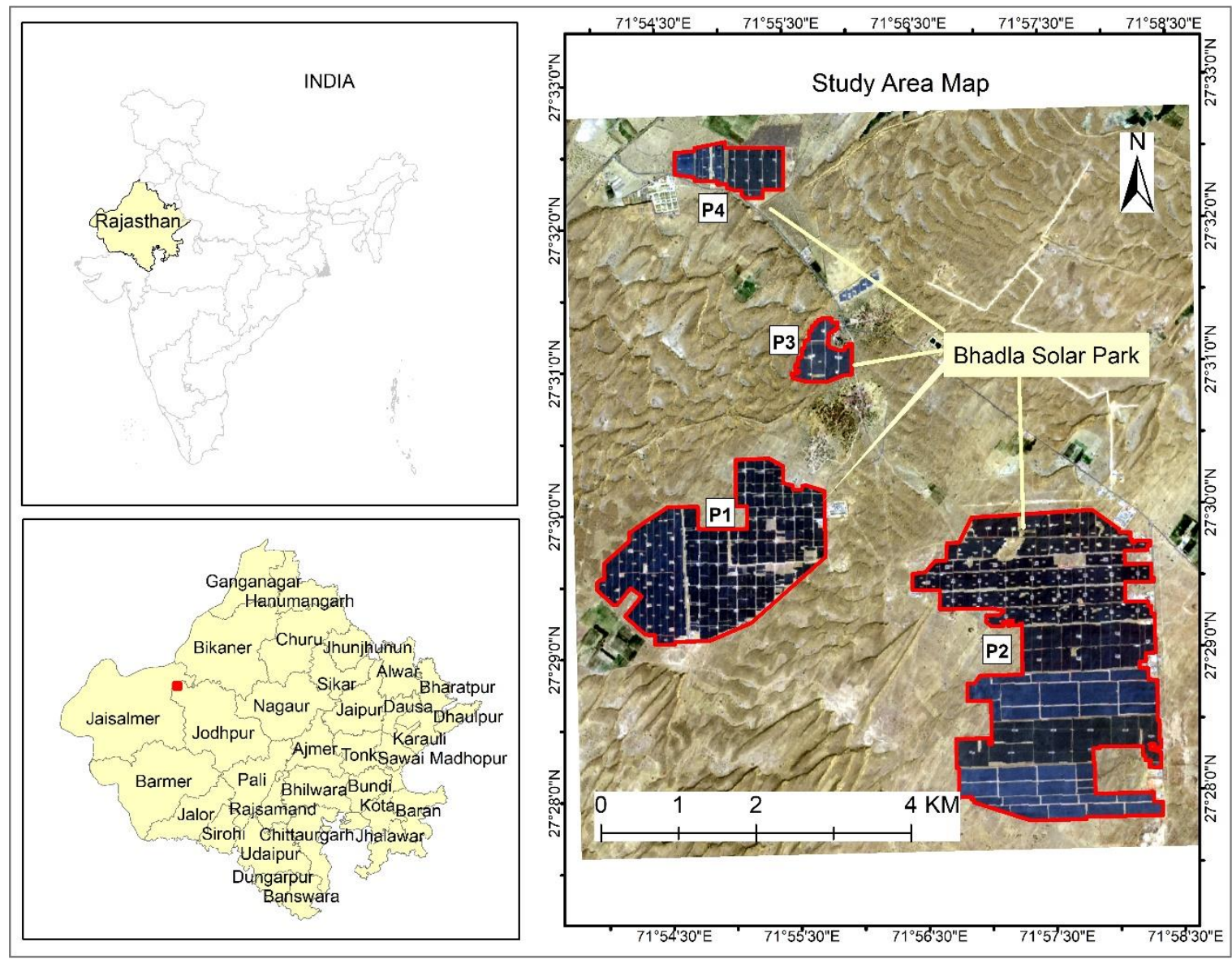

Figure 2. Location of Bhadla solar park in the state of Rajasthan in India and location of four photovoltaic (PV) parks (P1, P2, P3 and P4). Red square in lower left panel indicates the location of the study area in Rajasthan State.

The ultra-mega scale Bhadla solar park covering 37 plants spanning into four different phases, offers an excellent opportunity to study the soiling phenomenon using remote sensing technology. The monthly mean climatic conditions in the Bhadla region of Rajasthan is shown in Figure 3. Figure 3a illustrates the plot of the monthly average temperature and irradiance. Due to the cloudy atmosphere, the months of June and July show the lowest irradiance. This has been confirmed by visual inspection of satellite images available on the United States Geological Survey (USGS) Earth Explorer. The average monthly mean precipitation throughout the year is about $21 \mathrm{~mm}$. As the rainfall is low and inconsistent throughout the year, the monthly average precipitation, therefore, ranges from $2 \mathrm{~mm}$ to $84 \mathrm{~mm}$ and peaks around July and August [33]. Throughout the majority of the year, this area is subjected to westerly and north-westerly winds. Figure $3 b$ shows the monthly average wind speed which varies from $2.2 \mathrm{~m} / \mathrm{s}$ to $4.6 \mathrm{~m} / \mathrm{s}$ [34]. The highest wind speed is observed in the month of July. The fine particles of sand carried by the wind are deposited on the surfaces exposing the solar panel farm throughout the season. Furthermore, there are no man-made or natural windbreakers such as buildings, trees, and shrubs to block or alter the movement of the winds. Without the cover of vegetation and high-rise buildings in the face of winds, there is a continuous process of dune deposition. The regular exposure to winds makes the panels vulnerable to soiling. Figure 4 shows the field photographs of solar power panels collected during the field visit to the study area. Figure 4a,b illustrate clean PV solar panels and those soiled by sandy deposition, respectively. 

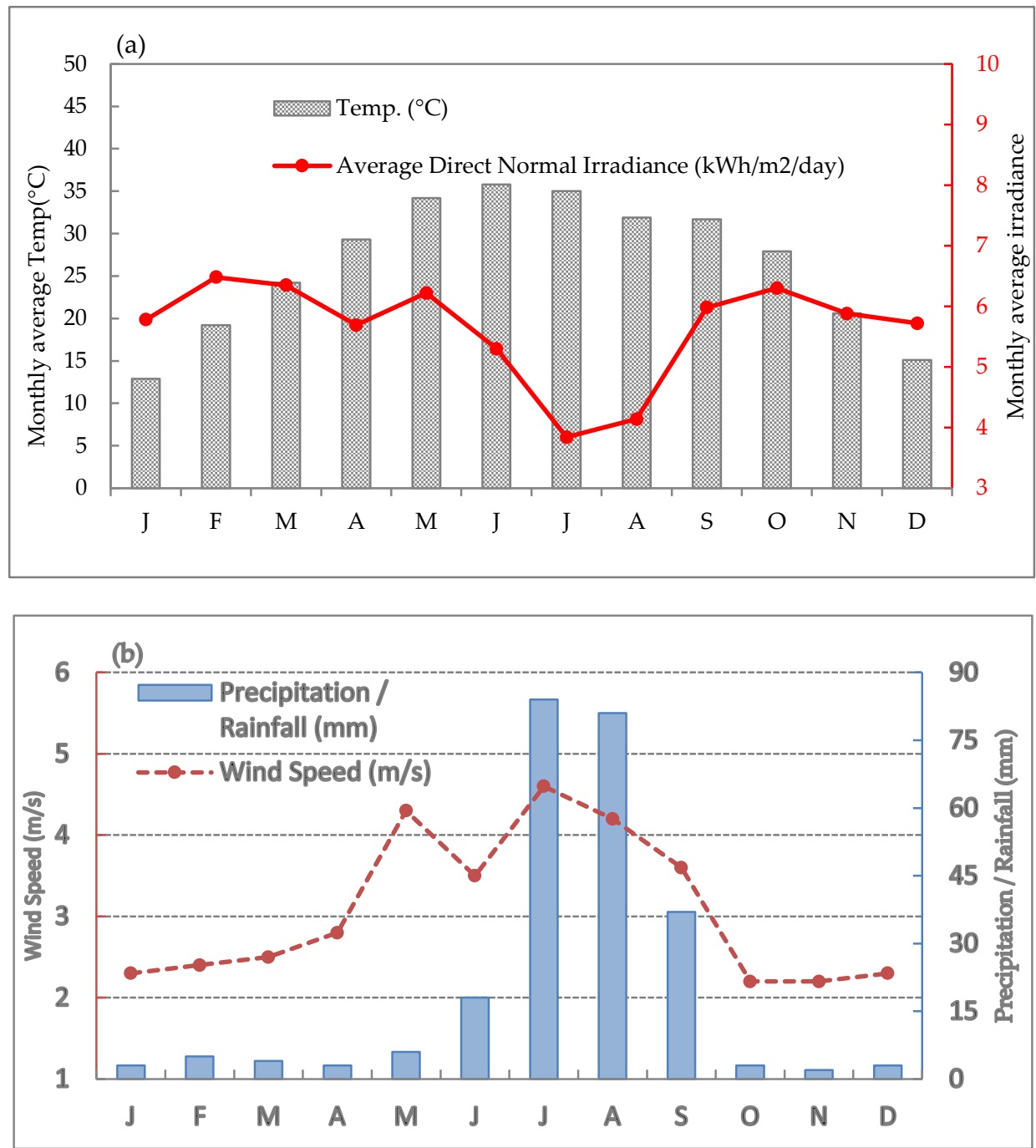

Figure 3. Monthly average climatology bar graph for Bhadla region of Rajasthan. (a) monthly average temperature (bar graph) and irradiance (thick line); and (b) graph showing monthly average wind speed (dashed line) and rainfall values (bar graph). Data source: [33,34].
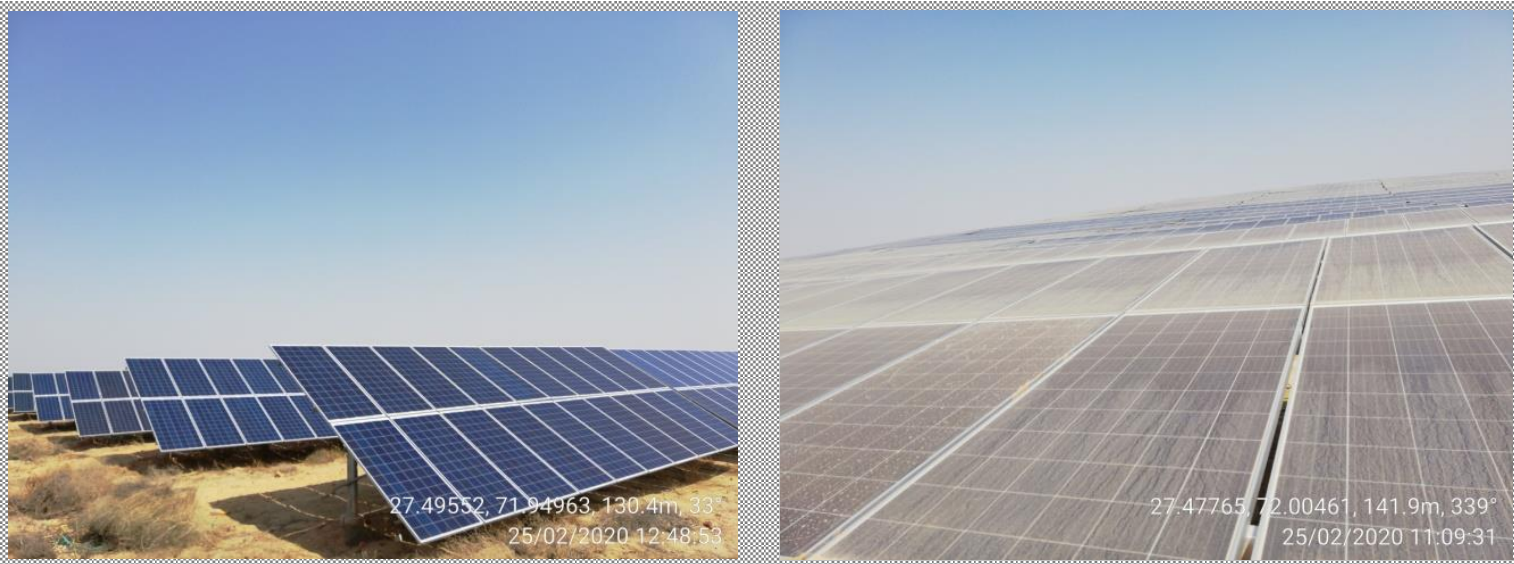

Figure 4. (a) Photographs showing the photovoltaic solar panels during the clean condition and (b) during the sandy deposition stage in the Bhadla Solar Park, Jodhpur District, Rajasthan State, India. 


\section{Materials and Methods}

This study attempts to provide an alternate model for scheduling the cleaning of solar panels. The field survey was conducted to collect the primary data on the soiling of solar panels, understand the cleaning approaches, and accumulate other firsthand information from the ground. To understand the plant operation, we conducted a total of eight interviews with the project managers and other operating staffs in four different solar plants at Bhadla. To estimate the extent of soiling on the panels between September 2017 and February 2019, we performed a time-series analysis of various soil indices using remote sensing technology (see following subsections). We aim to analyze and compare the multitemporal images to correlate the climatic effects with the soiling phenomenon.

\subsection{Satellite Data}

Readily available Landsat 8 and Sentinel-2 satellite data in the GEE platform were used for monitoring with a time frame from September 2017 to February 2019. The Landsat 8 launched in February 2013, is a joint National Aeronautics and Space Administration (NASA)/USGS program. Similarly, Sentinel-2 is an Earth observation mission of the European Union Copernicus Program that systematically acquires optical imagery at high spatial resolution. In this study, monthly median time series data were obtained from the Landsat 8 and Sentinel- 2 image collection. The list of images used in this study and acquisition details are provided in Table 1. To automate the satellite image analysis processes, we used the 'Google Earth Engine' (GEE) of Google Inc., an open cloud-based geospatial processing platform, designed mainly for planetary-scale environmental data analysis. The GEE platform combines a multi-petabyte catalog of satellite imagery and geospatial datasets, which allow users to visualize, manipulate, edit and create spatial data in an easy and fast way [35]. GEE incorporates a wide range of spatial manipulation tools which allows scientists, researchers, and developers to detect changes, map trends, and quantify differences on the Earth's surface [36]. The GEE can directly import Landsat 8 and Sentinel-2 images from its respective service provider and can be used for real-time processing.

Table 1. List of satellite data products used in this study and their date of acquisition. Sentinel-2 data includes monthly median values of the images.

\begin{tabular}{ccc}
\hline Data Source & $\begin{array}{c}\text { Date of Acquisition } \\
\text { (YYYY.MM.DD)/ } \\
\text { (YYYY.MM) }\end{array}$ & Number of Images \\
& $2017.09 .09 ; 2017.09 .25 ; 2017.10 .11 ; 2017.10 .27 ; 2017.11 .12 ;$ \\
& $2017.11 .28 ; 2017.12 .30 ; 2018.01 .15 ; 2018.01 .31 ; 2018.02 .16 ;$ \\
Landsat 8 (30 meters) & $2018.03 .20 ; 2018.04 .05 ; 2018.04 .21 ; 2018.05 .07 ; 2018.05 .23 ;$ \\
& $2018.06 .08 ; 2018.06 .24 ; 2018.07 .10 ; 2018.08 .11 ; 2018.09 .12 ;$ \\
Sentinel-2 (10 meters) & $2018.10 .14 ; 2018.11 .15 ; 2018.12 .17 ; 2019.01 .18 ; 2019.02 .03$ & 25 \\
PlanetScope (3 meters) & $2017.09 ; 2017.10 ; 2017.11 ; 2017.12 ; 2018.01 ; 2018.02 ; 2018.03 ;$ & \\
& $2018.05 ; 2018.06 ; 2018.07 ; 2018.08 ; 2018.09 ; 2018.10 ;$ & 18 \\
& $2018.11 ; 2018.12 ; 2019.01 ; 2019.02 ;$ \\
2018.01 .31 & 1 \\
\hline
\end{tabular}

The Landsat 8 satellite data consists of 12 spectral bands out of which, band 3 (green band), band 4 (red band) and band 7 (short wave infra-red 2 bands) were used to develop normalized difference sand index (NDSI) and ratio normalized difference soil index (RNDSI) with a spatial resolution of $30 \mathrm{~m}$. While in the Sentinel-2 satellite data, band 3 (green band) and band 12 (short wave infra-red 2), having respectively a spatial resolution of 10 meters and 20 meters, were used to calculate the dry bare soil index (DBSI). The DBSI also involved using band 4 (red) and band 8 (vegetation infrared edge) to generate the normalized differential vegetation index (NDVI). The data acquisition and semi-automated processing of the images were completed on the GEE platform and the direct results of the images were extracted from the cloud-based platform. Table 2 illustrates the specification and band details of Landsat 8, Sentinel-2 and Planet Scope satellites. 
Table 2. Band specifications of satellite sensors used in this study.

\begin{tabular}{|c|c|c|c|c|c|c|}
\hline Sensors & $\begin{array}{c}\text { Band } \\
\text { Number }\end{array}$ & $\begin{array}{c}\text { Bands } \\
\text { (Wavelength) }\end{array}$ & $\begin{array}{l}\text { Spatial Resolution } \\
\text { (Meters) }\end{array}$ & $\begin{array}{l}\text { Band Range } \\
(\mu \mathrm{m})\end{array}$ & $\begin{array}{c}\text { Radiometric } \\
\text { Resolution (bit) }\end{array}$ & $\begin{array}{c}\text { Revisit Cycle } \\
\text { (Days) }\end{array}$ \\
\hline \multirow{9}{*}{ A. Landsat 8} & & & & & 16 & 16 \\
\hline & 2 & Blue & 30 & $0.45-0.51$ & & \\
\hline & 3 & Green & 30 & $0.53-0.59$ & & \\
\hline & 4 & Red & 30 & $0.64-0.67$ & & \\
\hline & 5 & Near-Infrared & 30 & $0.85-0.88$ & & \\
\hline & 6 & SWIR 1 & 30 & $1.57-1.65$ & & \\
\hline & 7 & SWIR 2 & 30 & $2.11-2.29$ & & \\
\hline & 10 & TIR Sensor 1 & 100 & $10.6-11.19$ & & \\
\hline & 11 & TIR Sensor 2 & 100 & $11.5-12.51$ & & \\
\hline \multirow[t]{6}{*}{ B. Sentinel-2 } & & & & & 12 & 5 \\
\hline & 3 & Green & 10 & $0.54-0.57$ & & \\
\hline & 4 & Red & 10 & $0.65-0.68$ & & \\
\hline & 8 & Near-Infrared & 10 & $0.78-0.89$ & & \\
\hline & 11 & SWIR 1 & 20 & $1.56-1.65$ & & \\
\hline & 12 & SWIR 2 & 20 & $2.10-2.28$ & & \\
\hline \multirow{5}{*}{ C. Planet Scope } & & & & & 12 & Daily \\
\hline & 1 & Blue & 3 & $0.455-0.515$ & & \\
\hline & 2 & Green & 3 & 0.5-0.59 & & \\
\hline & 3 & Red & 3 & $0.59-0.67$ & & \\
\hline & 4 & Near-Infrared & 3 & $0.78-0.86$ & & \\
\hline
\end{tabular}

The validation of results was performed by adopting two customized techniques. Firstly, the land surface temperature (LST) generated from the Landsat 8 thermal bands were compared with results from the soil indices. Here the change in LST was expected for the region affected by the soiling phenomenon. Secondly, the PlanetScope high-resolution satellite images from "Planet Labs" were observed to view the soiling interfaces. PlanetScope data consists of the composite image of the red, green, blue (RGB) bands, which provides an actual view of the scene. Its spatial resolution is as high as 3 meters and is capable of daily acquisitions. We also performed an accuracy assessment using quantitative information of various indices against LST and PlantScope data.

\subsection{Methodology}

Figure 5 depicts the methodology deployed in this paper in the form of a flowchart. The study commenced by using GEE to detect soiling on solar PV panels by utilizing different types of indices based on the Landsat 8 and Sentinel-2 satellite data. 


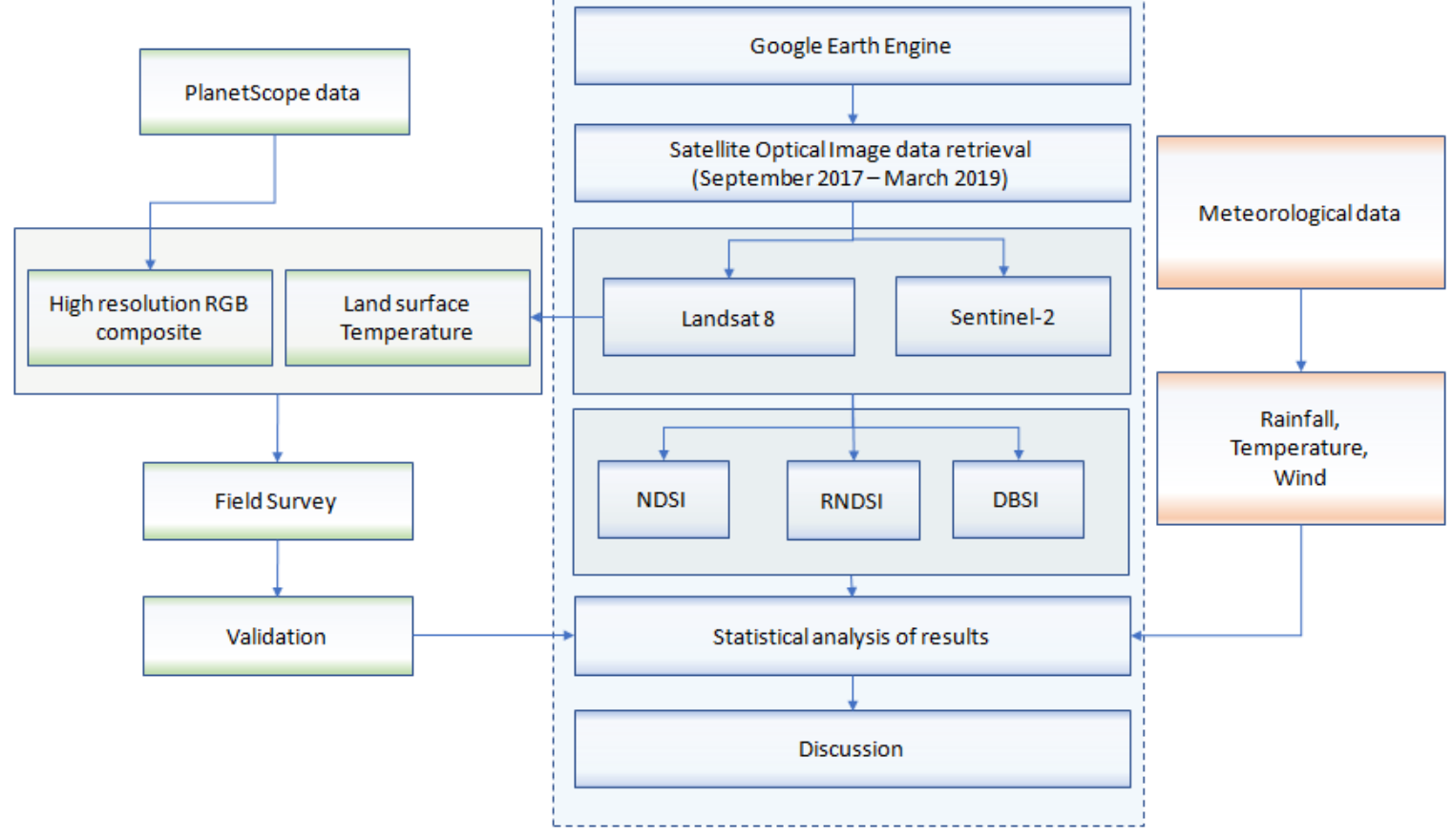

Figure 5. Flowchart of the study employed for the detection of soiling on PV solar panels.

\subsubsection{Normalized Difference Sand Index (NDSI)}

The normalized differential sand index (NDSI) was previously used for monitoring, mapping, and assessing the sand dune encroachment in some sites in the northern central part of Iraq over 21 years from 1988 to 2009 [27]. This index is helpful in the selection of areas suitable for control measures [27]. Similarly, in this study, NDSI was generated and applied in this field to identify the amount of sand deposition on solar panels. It is computed as the ratio of the measured intensities in the short-wave infrared (SWIR 2) and red (R) spectral bands, using Equation (1).

$$
\text { NDSI }=(\text { SWIR } 2-\text { Red }) /(\text { SWIR } 2+\text { Red })
$$

\subsubsection{Ratio Normalized Difference Soil Index (RNDSI)}

Apart from the sand index discussed above, we used another index to accomplish the purpose. The RNDSI can characterize the sandy desert, which can help in determining the level of fine sand deposition. It was developed for separating soil from impervious surface areas and vegetation so that it can serve as an input for the land use/land cover model (LULC) [26]. Unlike vegetation, string spectral responses do not exist for soil due to its complex physical and chemical composition and regional differences [26]. The two indices used are normalized differential soil index and tasseled cap transformation 1 (TC1) [26]. Here, RNDSI takes into consideration the brightness effect of the image that is derived from the tasseled cap transformation [26]. As a first task, the soil index is calculated using a green band and short wave infra-red 2 bands from the Landsat 8 satellite data.

$$
\mathrm{NDSI}_{2}=(\text { SWIR } 2-\text { Green }) /(\text { SWIR } 2+\text { Green })
$$

The above result i.e., $\mathrm{NDSI}_{2}$ is further transformed to normalized $\mathrm{NDSI}_{2}$ or $\mathrm{NNDSI}_{2}$ (see Equation (3)). Then the $\mathrm{NNDSI}_{2}$ is divided by a tasseled cap transformation brightness factor (NTC). The mathematical expression of RNDSI is as follows:

$$
\mathrm{NNDSI}_{2}=\left(\mathrm{NDSI}_{2}-\mathrm{NDSI}_{2 \mathrm{~min}}\right) /\left(\mathrm{NDSI}_{2 \max }-\mathrm{NDSI}_{2 \mathrm{~min}}\right)
$$


and,

$$
\begin{gathered}
\mathrm{NTC1}=\left(\mathrm{TC} 1-\mathrm{TC} 1_{\min }\right) /\left(\mathrm{TC} 1_{\max }-\mathrm{TC} 1_{\min }\right) \\
\text { RNDSI }=\left(\mathrm{NNDSI}_{2}\right) /(\mathrm{NTC} 1)
\end{gathered}
$$

$\mathrm{NDSI}_{2 \min }=-1 ; \mathrm{NDSI}_{2 \max }=1 ; \mathrm{TC} 1_{\min }=10,000 ; \mathrm{TC}_{\max }=50,000$.

The range of RNDSI values depends on the $\mathrm{TC} 1_{\min }$ and $\mathrm{TC} 1_{\max }$ values. In this case, the range of values selected for tasseled cap transformation brightness was from 10,000 to 50,000. Consequently, the final output, that is, the RNDSI has values that vary from 0 to 3 . The higher the value of RNDSI, the higher is the amount of soiling.

\subsubsection{Land Surface Temperature (LST)}

Landsat 8 thermal bands (band 10 and 11) measure the energy emitted from the earth's surface and can be used to retrieve the LST. The presence of sand particles on PV panels can show the change in LST [37]. The LST depends on the land surface type because of variations in the emissivity from heterogeneous surfaces such as vegetation cover, built-up, and bare soil. The clean PV panels and arid sand dunes are continuously exposed to sunlight for a long time. This makes the surface temperature of panels and bare lands to rise. However, when fine sand particles carried by a sandstorm or wind are accumulated on the panel surface, the overall panel surface temperature changes. Wind carried sand particles have comparatively low temperatures; therefore, settlements of sand particles make the region cooler. With this principle, a variation on solar panel surface value can be linked with the presence of the sand layers. However, as the Landsat 8 derived LST has a coarse resolution in comparison to the size of the PV panels, we analyze the pattern of the LST rather than specific values.

In this study, a two-step process was used to generate LST from the Landsat 8 data [38]. In the first step, the atmospheric correction was carried out by computing necessary atmospheric parameters. In the second-step, land surface emissivity was calculated based on studies carried by [39-41]. Furthermore, LST was obtained by using TIRS band 10 with a mono-window algorithm [42].

\subsubsection{Dry Bare Sand Index (DBSI)}

The Dry bare soil index (DBSI) is used to identify bare soil from arid and semiarid regions-especially areas having a dry climate. A recent study [25] developed this index to map built-up and bare areas in dry climates from the Landsat 8 data. The DBSI algorithm was used in determining barren land and differentiating it from other built-up areas [25]. In this study, the same algorithm was implemented on GEE values by using Sentinel-2 data. Sentinel-2 images have higher spatial resolution compared to Landsat; hence, it was more precise in detecting sand deposition layers. The proposed equation for bareness area in a dry climate is the inverse of the modified normalized difference water index [25].

$$
\begin{gathered}
\text { DBSI }=(\text { SWIR } 1-\text { Green }) /(\text { SWIR } 1+\text { Green })-\text { NDVI } \\
\text { Where }, \text { NDVI }=(\text { NIR }- \text { Red }) /(\text { NIR }+ \text { Red })
\end{gathered}
$$

The DBSI results' values range from -2 to +2 , and higher numbers represent a high degree of the bareness of soil [25]. In previous studies, the threshold value was used for differentiating bare soil and non-bare soil areas in the city of Erbil, Iraq [25]. Based on a test carried out with a sample of bare soil pixels, a DBSI value of 0.26 and higher was delineated as bare soil [25]. With this background, we used DBSI with the assumption that it can differentiate the soiled pixels and clean pixels in our study area. 


\section{Results}

\subsection{Spatial Correlation between NDSI, and RNDSI with LST}

NDSI, RNDSI and LST are mapped over the spatial domain to detect soiling on the panels. Figure 6 shows the images taken during September 2017. Consequently, this year the panels were expected to receive a high level of soil deposition since self-cleaning systems were not installed (in the initial stages). In the initial stages, the cleaning process was carried manually using water. The Ecoppia E4 panel cleaning robots were installed and operational on some of the panels since February 2018 [43]. The company deployed around 2000 units of Ecoppia E4 robots in two different phases of the park [43]. These robots move over the surface of the panels and sweep away dust from it [44]. Figure 6a,c show NDSI values based on Landsat 8 data, acquired in September 2017. High values correspond to the high level of sand deposition on the surface of panels [27]. Some part of the study area shows low values of NDSI, which corresponds to the clean panels. Uneven distribution of values can be seen over panel surfaces. These variations with high values can be visually ascribed as sand deposition. The sand deposition also affects temperature. Hence, a change in temperature is also expected [37]. Figure 6b,d show the LST based on the Landsat 8 data. The visual comparison between the land surface temperature and NDSI of the study area can be seen in Figure 6.

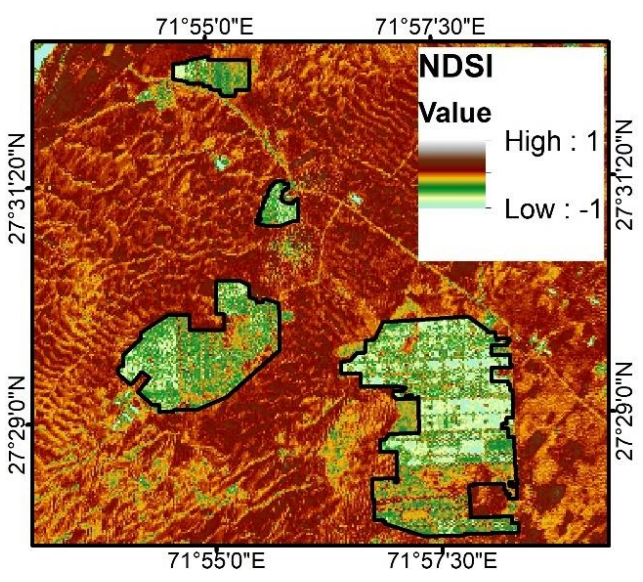

(a) L8 NDSI (9th September 2017)

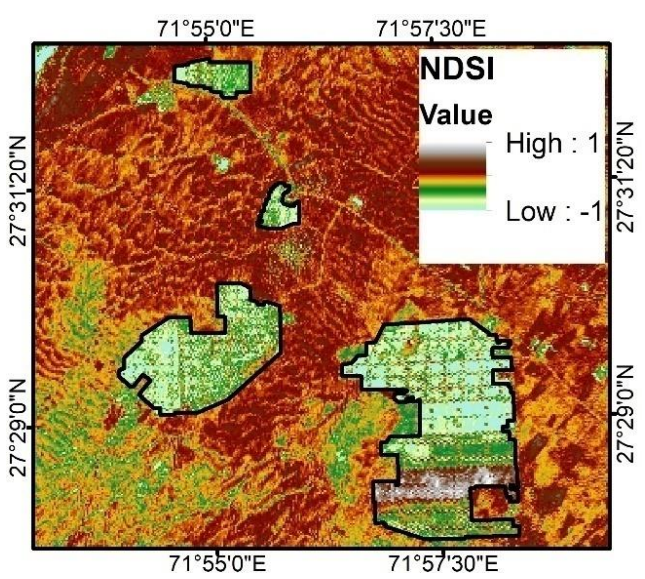

(c) L8 NDSI (25th September 2017)

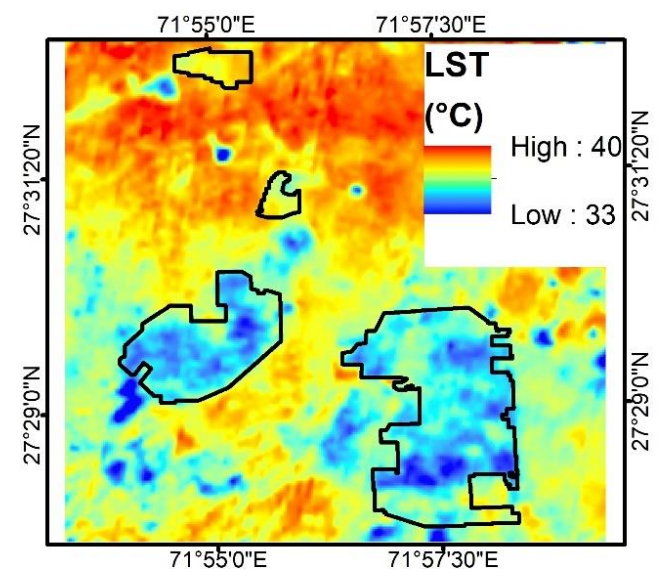

(b) L8 LST (9th September 2017)

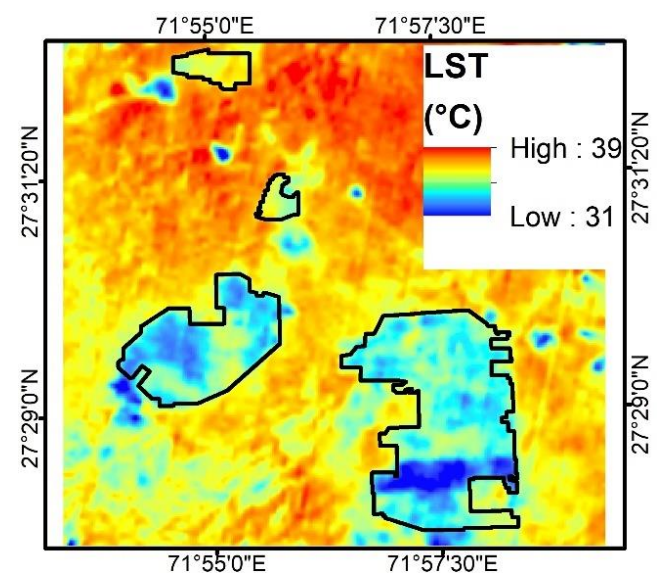

(d) L8 LST (25th September 2017)

Figure 6. Visual comparison of sandy deposition on a solar farm (described within the black border). High values of normalized difference sand index (NDSI) shown in (a) and (c) within the black border indicates the location of sandy deposition. Landsat 8 generated land surface temperature (LST) pattern during the same period shows the lowest temperature (bluish tints) for the sandy deposition areas on top of the panels (b) and (d). 
The pattern of LST variation is quite similar to the variation of pixels values on the panel surface. Regions having low temperature in the LST map coincide with regions having high NDSI values. A case study experiment done by Márquez and Ramírez [37], reveals that thermographic analysis is an effective method in the detection of accumulated dust particles carried by the wind on the solar panels. Based on emissivity analysis, the value of the emissivity of dust was revealed to be very low. As a result, the brightness temperature of the surface falls. Hence, the temperature decreases when the dust and sand gets accumulated [37], and under the larger areas with dust, the temperature dips further [37]. A similar pattern is observed in the results shown in Figure 6. Correspondingly, Figure 7 shows the NDSI of Landsat 8 images acquired in May 2018 and June 2018 which have a lower sand deposition. The solar power plant and its surrounding area show a low variation in NDSI values on the surface of panels compared to images taken in September 2017. The NDSI and LST results are indicative of uniformity along these surfaces. This implies that the panels were cleaner in 2018 because of the use of robots or by other means [45].

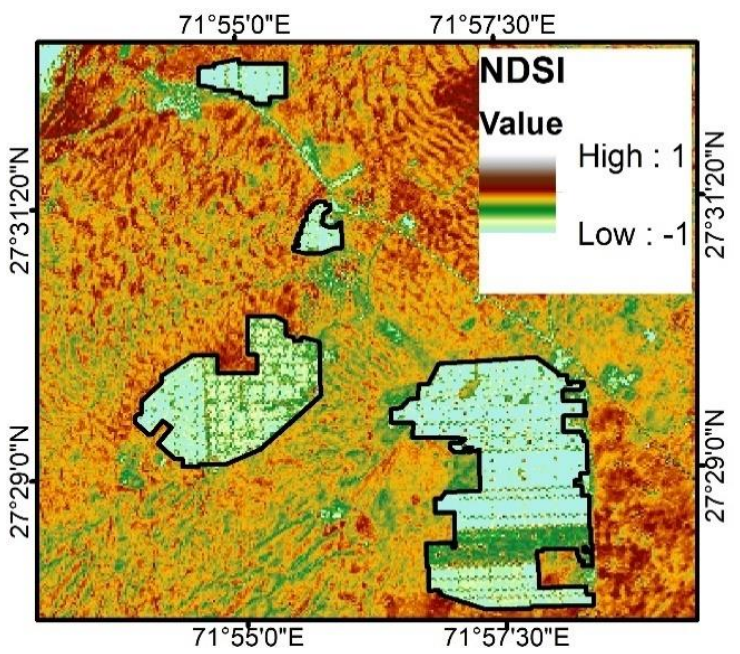

(a)L8 NDSI (23rd May 2018)

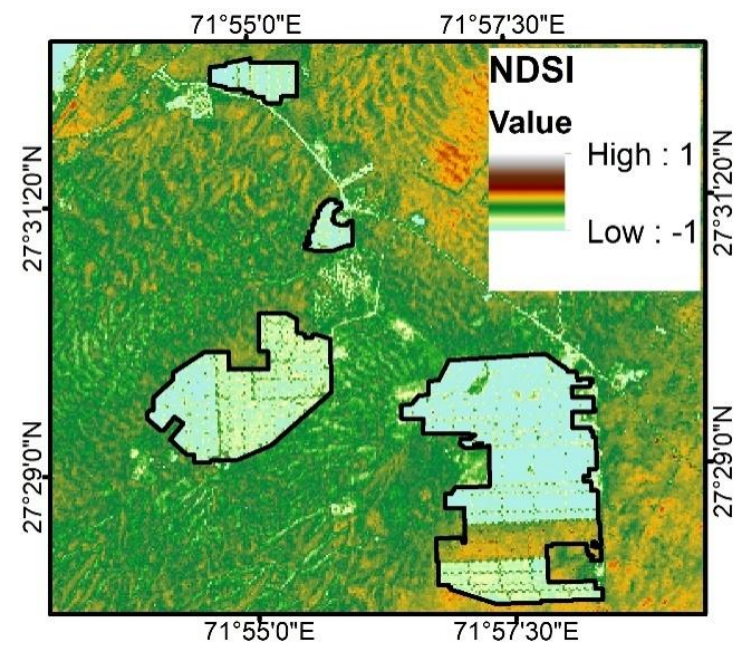

(c)L8 NDSI (8th June 2018)

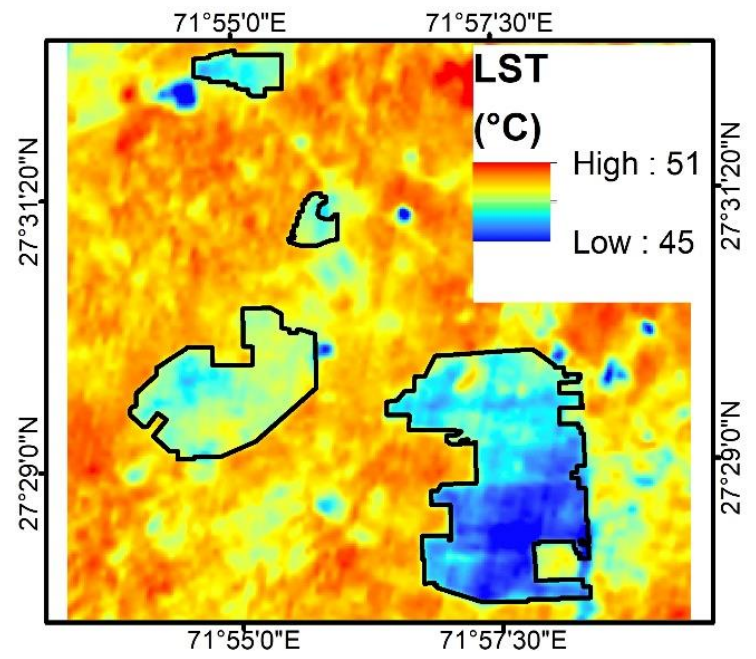

(b) L8 LST (23rd May 2018)

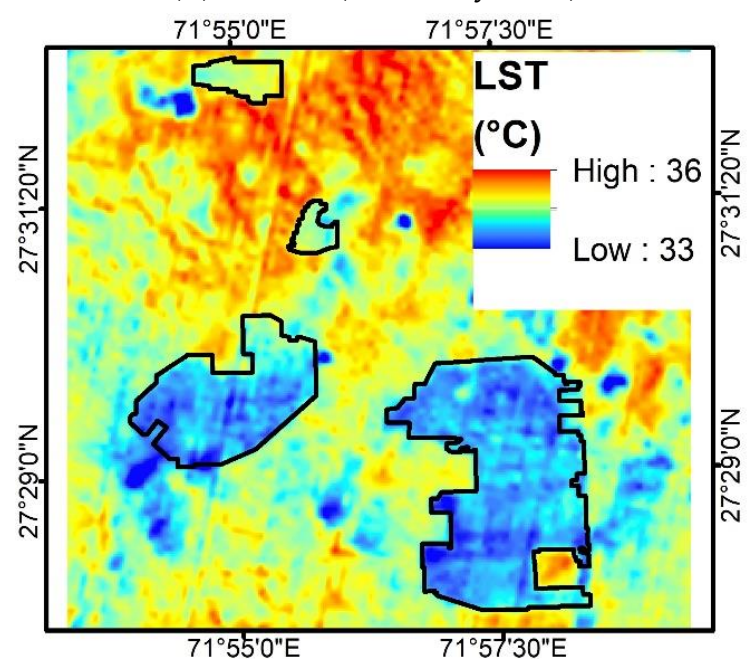

(d) L8 LST (8th June 2018)

Figure 7. Visual comparison of sand deposition on the solar farm based on NDSI and LST after cleaning. The figure shows a similarity between NDSI (Figure 7(a), 7(c)) with sand deposition variation and LST pattern of Figure 7(b), 7(d), respectively.

We further investigated RNDSI to see the pattern of soiling in the study area, as shown in Figure 8. The results from RNDSI show similar outcomes as shown in NDSI based analysis. Since RNDSI is 
a ratio of soiling index and brightness, it dampens the built-up effect and emphasizes the soiling effect. The images acquired in December 2017 and January 2018, show high values of RNDSI varying between 0.99 and 1.87, as shown in Figure 8a,c. On the other hand, during May 2018 and June 2018, the values of RNDSI show lower values, which vary between 0.61 and 0.82 , as shown in Figure 8e,g. A similar distribution pattern of NDSI values are observed in 2017 and 2018, displayed in Figures 6 and 7. In Figure 8, the RNDSI-generated greyscale raster images highlight some bright clusters in the study area, which represents highly soiled regions. We further compared the mean value of NDSI and RNDSI in the study site from September 2017 to February 2019 as shown in Figure 10.

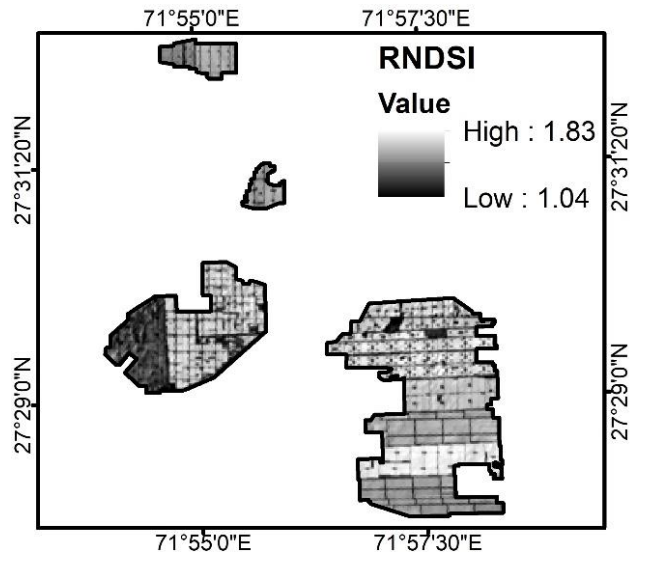

(a) RNDSI 30th December 2017

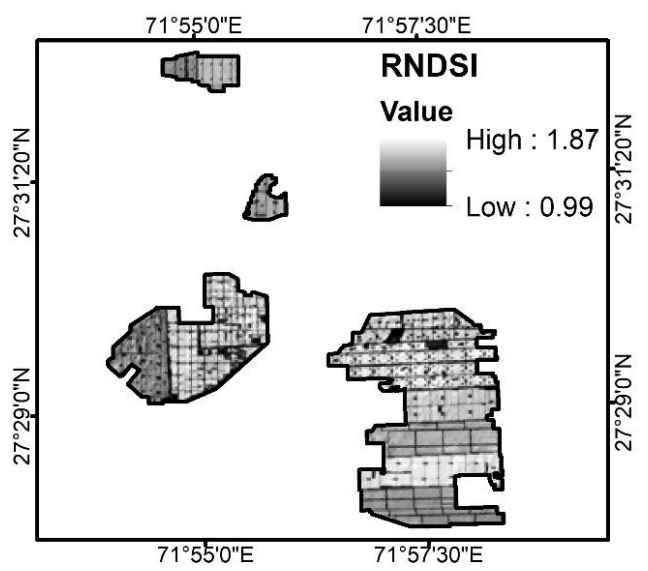

(c) RNDSI 15th January 2018

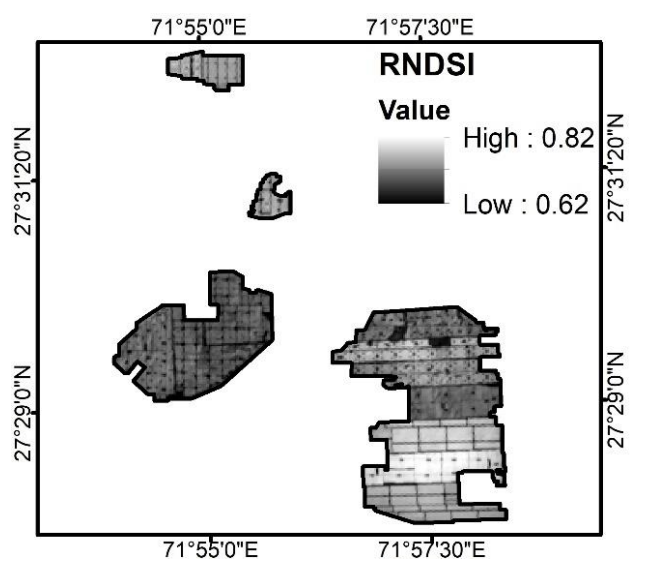

(e) RNDSI 23rd May 2018

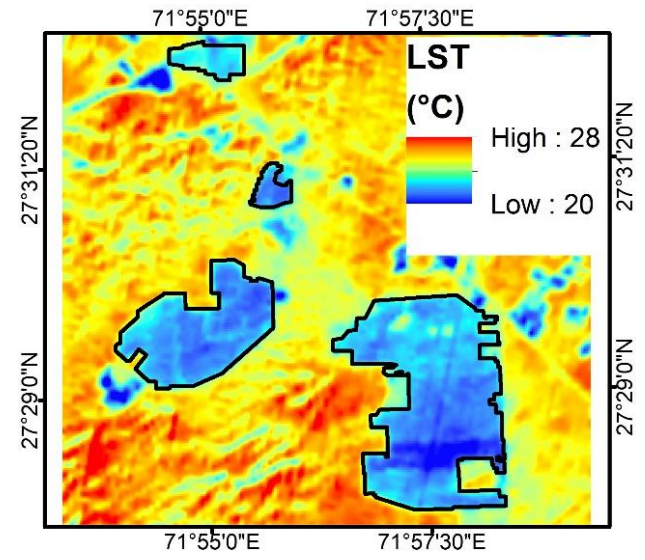

(b) L8 LST 30th December 2017

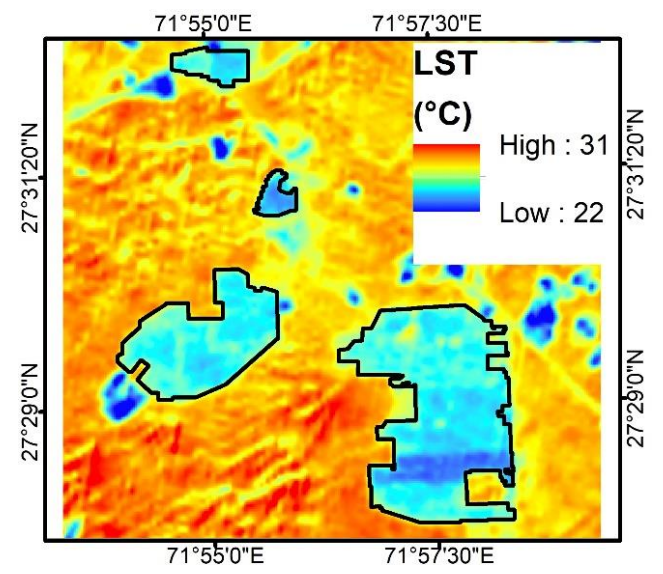

(d) L8 LST 15th January 2018

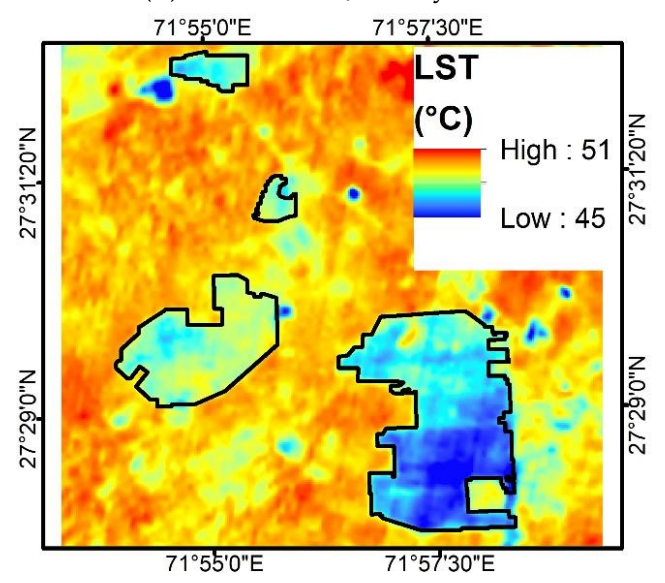

(f) L8 LST 23rd May 2018

Figure 8. Cont. 


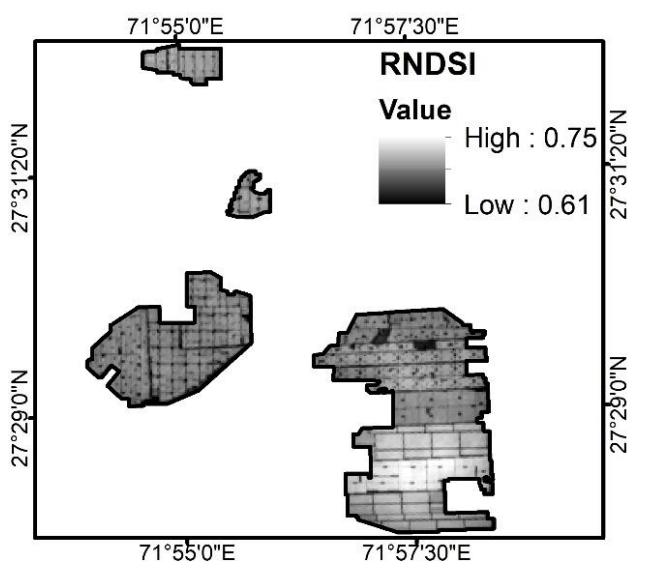

(g) RNDSI 8th June 2018

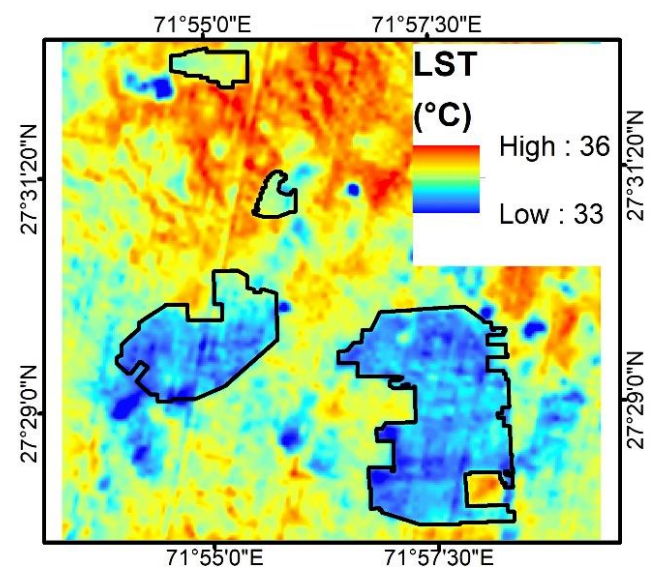

(h) L8 LST 8th June 2018

Figure 8. Landsat 8 spatial distribution of soiling patterns using ratio normalized difference soil index (RNDSI) along with LST at different times after the installation of panels. The figure shows results of RNDSI in Figure $8(\mathbf{a}), 8(\mathbf{c}), 8(\mathbf{e}), 8(\mathbf{g})$ with LST in Figure $8(\mathbf{b}), 8(\mathbf{d}), 8(\mathbf{f}), 8(\mathbf{h})$ respectively.

Although Landsat 8 based LST cannot provide precise information about exact temperatures, it has been widely used to see the temperature pattern and their variations. When we consider entire solar farms, certain variations of temperature patterns were seen on the panel surfaces. Due to the coarse resolution of LST data when compared to the size of solar PV panels, in this study, the temperature pattern was qualitatively analyzed rather than quantified as a specific temperature range [37]. Continuous exposure of clean PV panels and fine sand particles to solar light for a long time causes an increase in the temperature of sand particles [46]. However, when the fine sand particles carried over through a sandstorm or wind are accumulated on the panel surface, the overall panel surface temperature changes. Furthermore, the wind carrying the sand particles has comparatively lower temperatures, and therefore, the settlements of sand particles make the region significantly cooler [37]. Subsequently, through the use of this principle, a comparison of the results with LST was helpful for validation. The variation of temperatures observed in 2018-2019 indicates a more uniform texture when compared to 2017. This implies that there was less sand deposition in 2018-2019. The inference of this observation is also closely related to the results obtained from the NDSI.

\subsection{Sand Layer Detection Using DBSI}

Figure 9 indicates the result based on the dry bare soil index (DBSI) using Sentinel-2 data. We tried various values of DBSI to identify the threshold values to detect soiling on the PV panels. The threshold value of DBSI is 0.26, as highlighted in red in Figure 9. It is an easy and clear way of information extraction and analysis. Visually, it can be inferred through the results as some patches and strips of affected areas are noticeable. In January, February, March, and May of 2018, many concerned areas are readily visible. However, the results for other months, such as June 2018, August 2018, November 2018, and February 2019, reveal clean panels with the exception of some bright patches. 


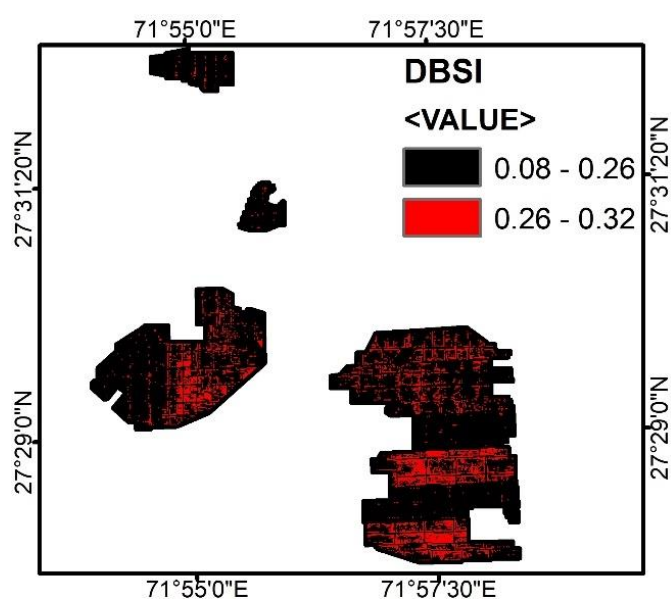

(a) DBSI January, 2018

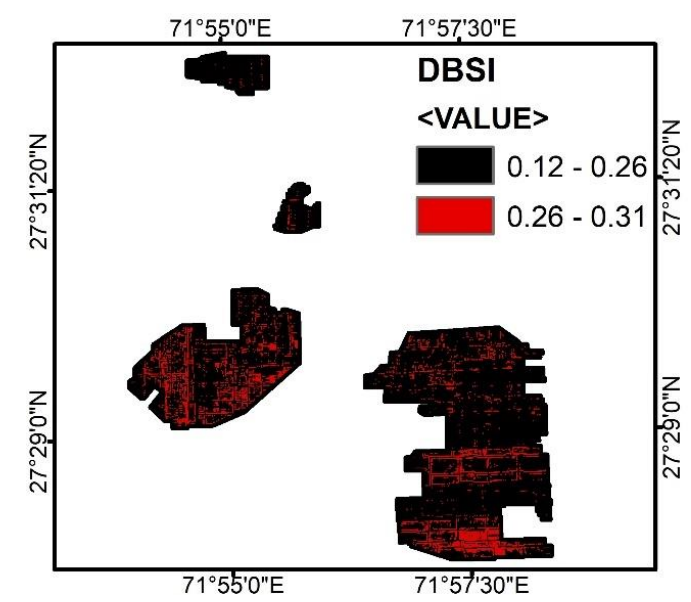

(c) DBSI March, 2018

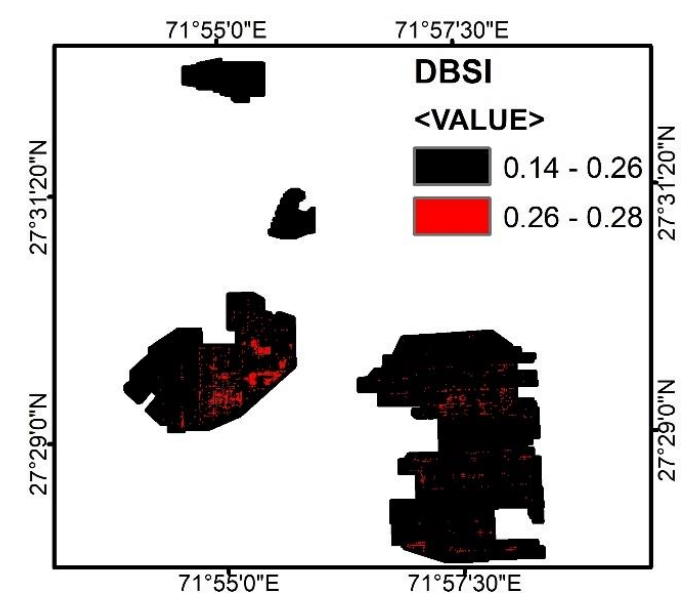

(e) DBSI June, 2018

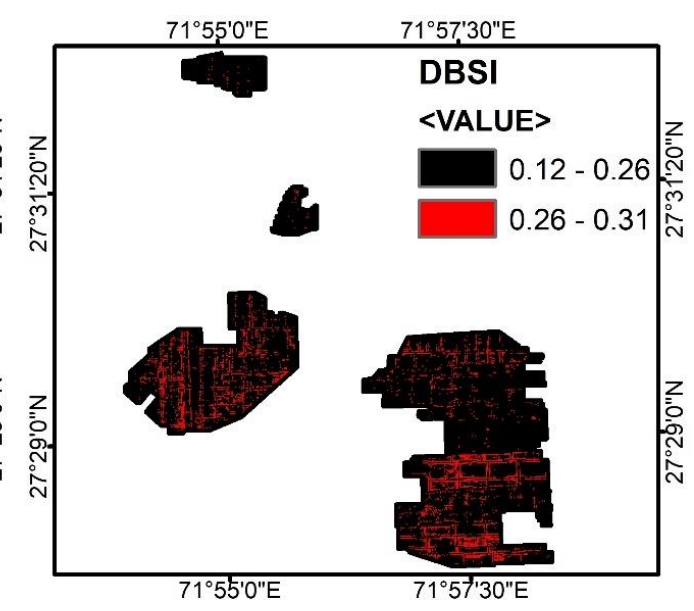

(b) DBSI February, 2018

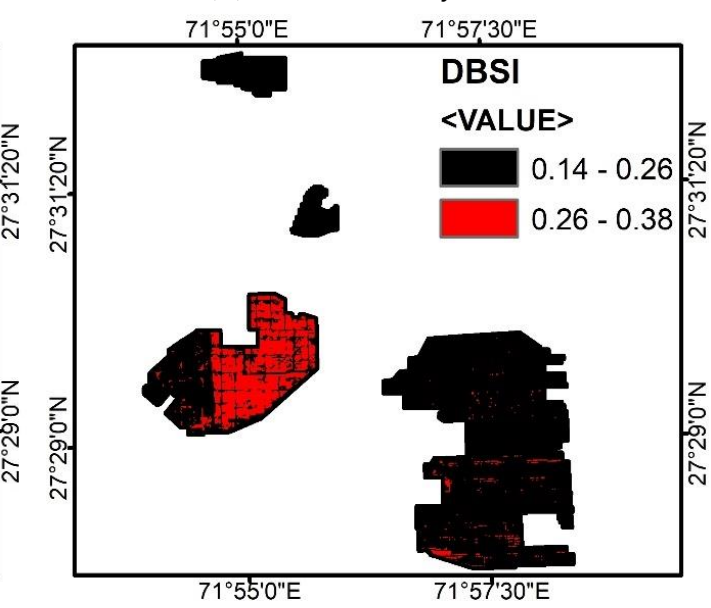

(d) DBSI May, 2018

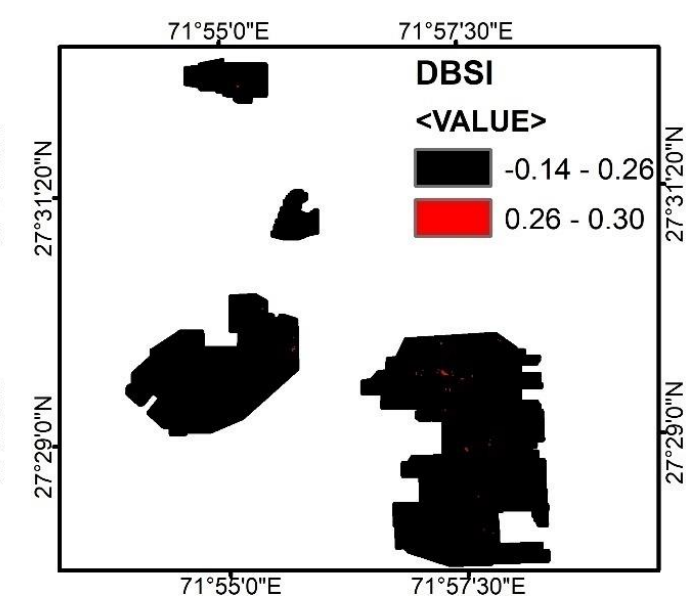

(f) DBSI August, 2018

Figure 9. Cont. 


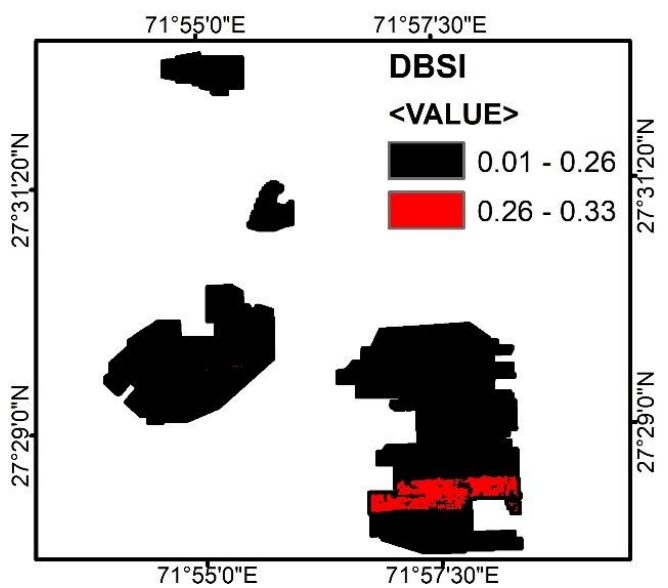

(g) DBSI November, 2018

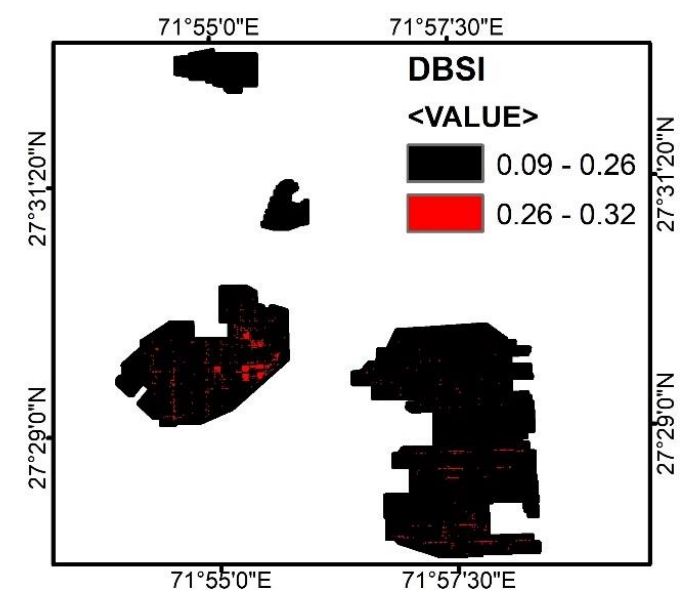

(h) DBSI February, 2019

Figure 9. Sentinel-2 Spatial distribution of soiling patterns using dry bare soil index (DBSI) at different times after the installation of panels. Images highlight the affected area that is distinguished by applying threshold value. Figure 9(a), 9(b), 9(c), 9(d) show high soiling compared to Figure $9(\mathbf{e}), 9(\mathbf{f}), 9(\mathbf{g}), 9(\mathbf{h})$.

\subsection{Time Series Behaviour of Sand Indices}

Along with the visual interpretation, we also performed a zonal statistical calculation to display the quantitative information for clarity. The graphical representation of NDSI, RNDSI, and DBSI was able to better track the behavior of soiling since the period when the plant was established. The four-study site of the solar farm as shown in Figure 2 was considered as one unit and monitored. Figure 10 illustrates the mean NDSI and RNDSI from September 2017 to February 2019.

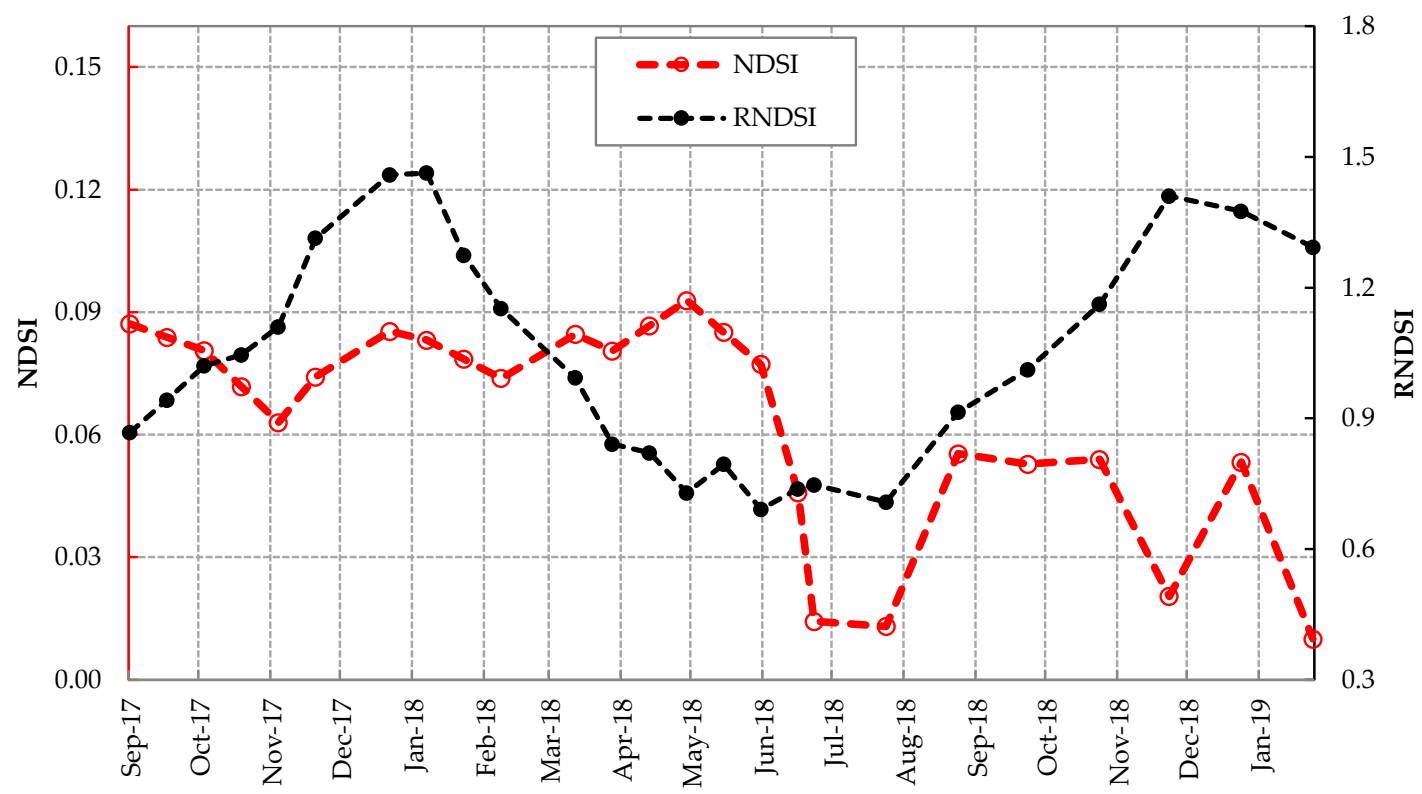

Figure 10. Comparison of mean NDSI values and mean RNDSI values of study site from September 2017 till February 2019.

The distribution of values of indices throughout the time frame in Figure 10 is uneven. Such variations arise because the cleaning process was not carried out daily. The cleaning processes schedule and performance are decided by respective plant owners [29]. Furthermore, Landsat 8 data are not available on consecutive days, hence monthly data were considered. As a result, higher variations were observed in the graphical readings. However, a change in the trend of the lines is observed at the 
later stages. The mean value of NDSI is higher until April 2018. The decreasing pattern of the mean value of NDSI is observed until February 2019.

Unlike NDSI, the RNDSI graph displays a nondrastic change in the values. Furthermore, the RNDSI values show consistency during the same months of the year. Additionally, there is another similarity like graphs with NDSI. A continuous increase in the value of RNDSI is seen from September 2017 to January 2018. The RNDSI value reaches its maximum mean at an index value of 1.5. After that period, a continuous decrease in the values until July 2018 is observed. This dip in the graph significantly coincides with the drop observed in NDSI during the same period. Nonetheless, its values keep on increasing thereafter.

Figure 11 shows the percentage area covered by soiling using the DBSI index from September 2017 to February 2019. There are few peaks observed in the first half of the year in 2018, this indicates a high level of soiling, as shown in Figure 11. Around July 2018, a drop in the DBSI value near to zero was observed. Low soiling was observed from July 2018 to February 2019 when compared to January 2018 to June 2018. This may be due to the use of robotic systems for cleaning the PV panels to improve efficiency. The DBSI graph also shows a similar trend to NDSI and RNDSI. The change in nature of the graph in all three indices is observed around February, March, and April in 2018, with a decreasing trend thereafter.

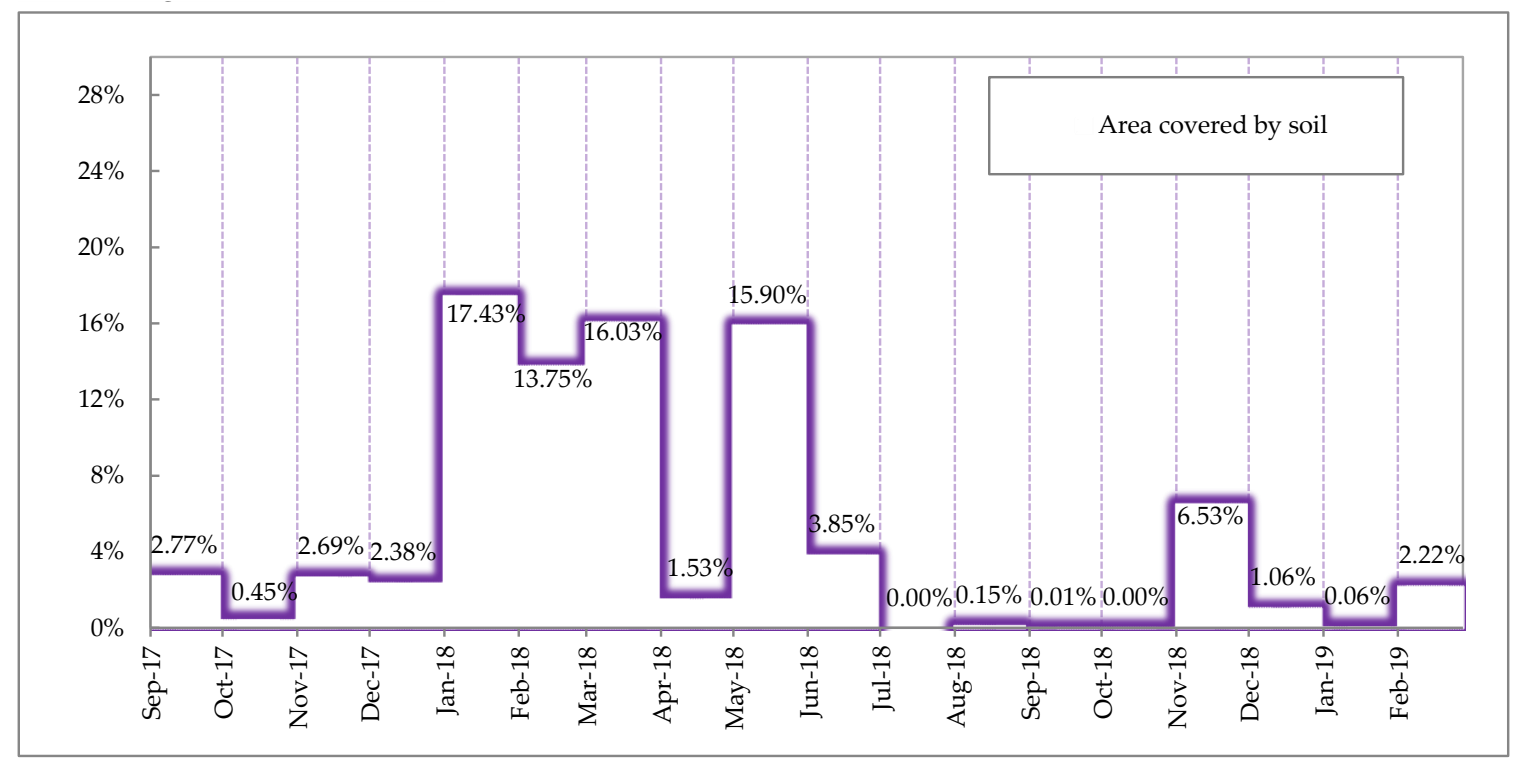

Figure 11. DBSI derived percentage area covered by soil.

Figure 12 describes the index values for each PV park in the study area during dry and wet seasons. Plots P1, P2, P3, and P4 are described in Figure 2 with subscripts: ' $d$ ' and ' $w$ ' for dry and wet seasons, respectively. For the dry season, the mean value of indices was calculated for December, January, February, March, and April. During this period the study area experiences a low level of precipitation. On the other hand, the mean value of indices was calculated for June, July, and September during the wet season, when the precipitation is high. In the case of NDSI and RNDSI, the mean index value of plots in the dry season are higher than that in the wet season. However, the mean values of DBSI are almost similar for both the dry and wet seasons. Still, when compared to the wet season, the mean DBSI shows a lesser variation in the dry season. 


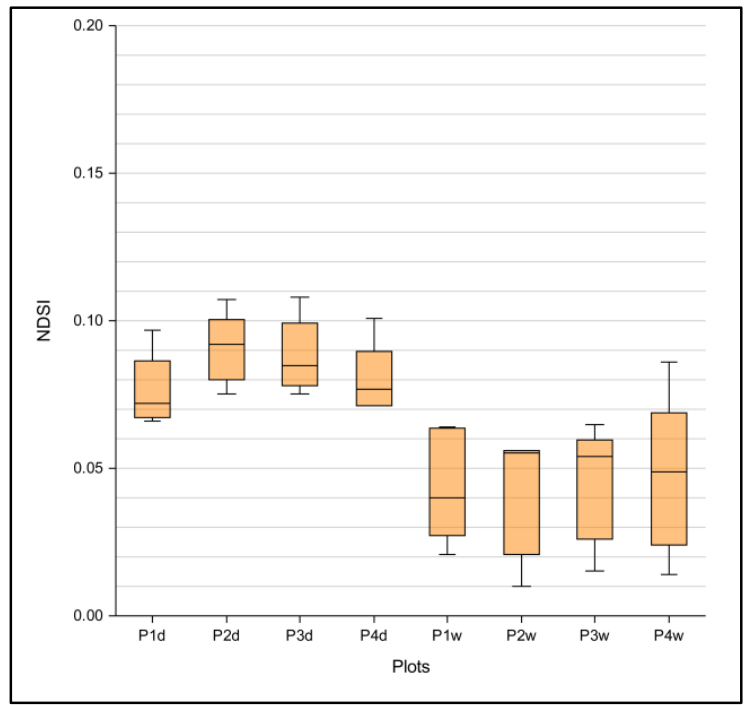

(a) NDSI

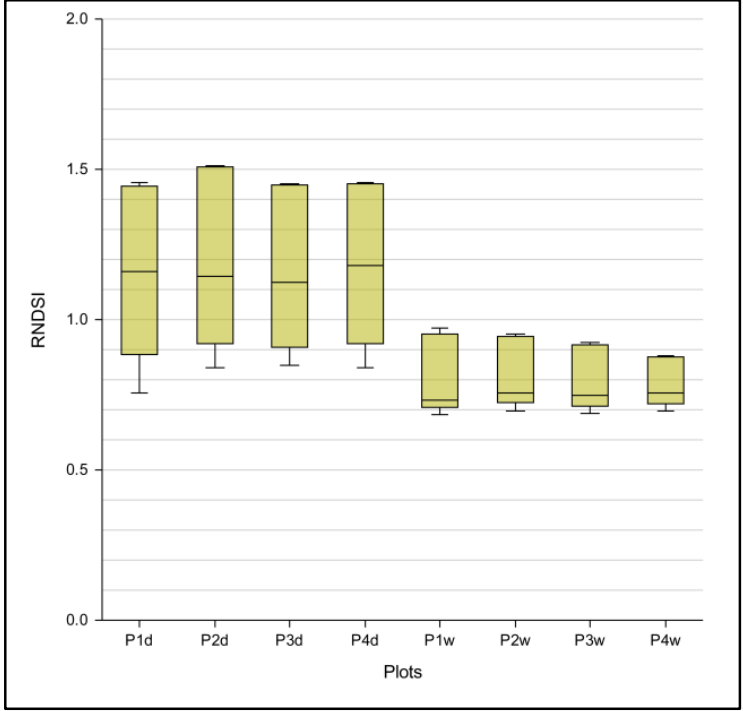

(b) RNDSI

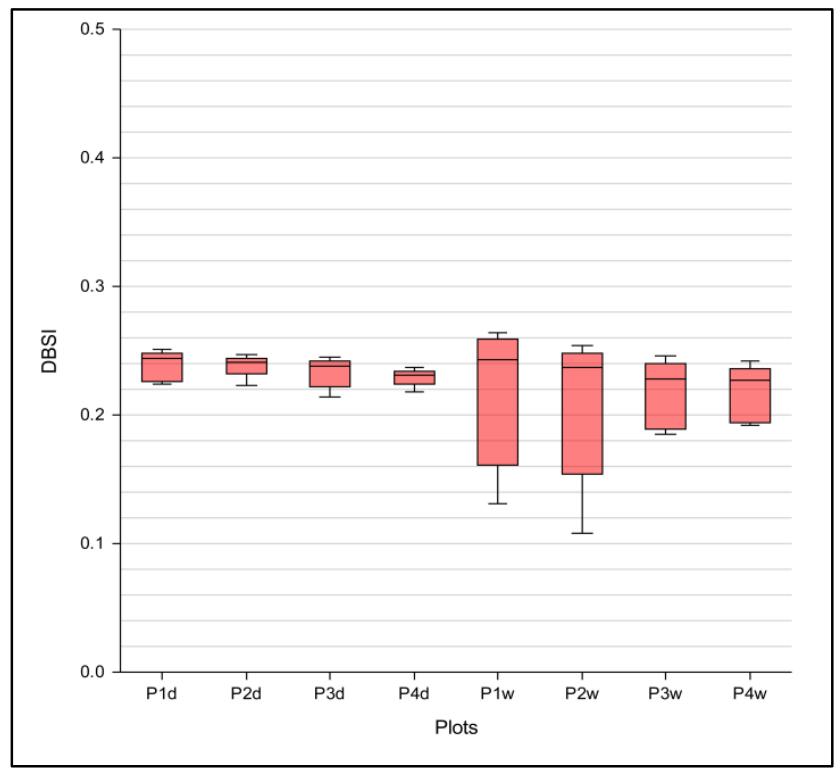

(c) DBSI

Figure 12. Mean value of (a) NDSI, (b) RNDSI and (c) DBSI of four plots in the study area during the dry and wet season. P1d, P2d, P3d and P4d are four PV parks in the dry season and P1w, P2w, P3w and $\mathrm{P} 4 \mathrm{w}$ in the wet season.

All three indices show similarity in their graphical representation of soiling during the whole study period, i.e., 2017-2019, as shown in Figure 12. For each index shown in Figure 12a-c, the peak and lowest values were observed in the dry and wet periods, respectively. From Figures 10 and 11 , it can be observed after June 2018, results show a gradual decrease in the indices values. Figure $3 \mathrm{~b}$ shows that the average rainfall in the study area is highest around July and August, which is the same period when the lowest values in indices were recorded. The reason for this lies in one of the properties of sandy soil $[47,48]$. The sand dunes have high moisture absorbing capacity [48]. Therefore, during the high precipitation periods, sand dunes lose their cohesion. Hence, it is less affected by wind erosion [47,48]. Dijk et al. [49], reported that moisture in the atmosphere dampens the ability of wind to carry fine sand particles. Although more wind is expected in July and August as displayed in Figure 3b, 
the amount of soil drifted by it is lesser. Thus, a low level of sand dune deposition is detected in July and August during the rainy season. In the case of NDSI, the soiling level in September 2017 is different than in the same month of 2018. Therefore, this difference in the same season exists as there were no self-cleaning robots installed in September 2017 [43]. The meager changes among the values exist because of different index gauges with varying soil types and properties. Nonetheless, the natures of the three indices are considerably related to each other and are useful in detecting soiling on PV panels.

\subsection{Comparison of NDSI, RNDSI and DBSI}

Explicit and sharp images with a high spatial resolution were acquired from PlanetScope to monitor the soiling phenomenon more closely. The three-meter spatial resolution PlanetScope data with four bands (RGB, NIR) was also analyzed to see the soiling pattern. Figure 13 shows the comparison of NDSI, RNDSI and DBSI with PlanetScope data for the validation. Figure 13a shows a magnified view of a particular section of the PV panels with sand deposition. With keen observation, a slight variation is observed on the surface. This section has a flimsy white trail and has patches on its rectangular base, as shown in Figure 13a. The same section on the NDSI raster layer, displayed in Figure 13b, highlights slightly higher values. Similarly, a comparison of RNDSI with PlanetScope is also displayed in Figure 13a,c. Unlike NDSI, the values of pixels along the rectangular base are rather different. The dark patch on the high-resolution image has high values on the RNDSI layer. It indicates that the region has a high level of sand deposition compared to other parts. The result of, DBSI shown in Figure 13d however, is similar to NDSI, showing a high index value on bright patches. All three indices practically adhere to the data. However, a finer observation revealed that NDSI and DBSI are more sensitive to visual observation. The dark patch on high-resolution PlanetScope data was contrasting with RNDSI results. The area with the dark and bright patches identified with PlanetScope data was further investigated to see the spectral reflectance properties of Landsat 8 data at a wavelength ranging from $0.4 \mu \mathrm{m}$ to $2.2 \mu \mathrm{m}$. The study of spectral responses is also useful to validate minute differences in the sand layer to compare accuracy between NDSI, DBSI, and RNDSI qualitatively.

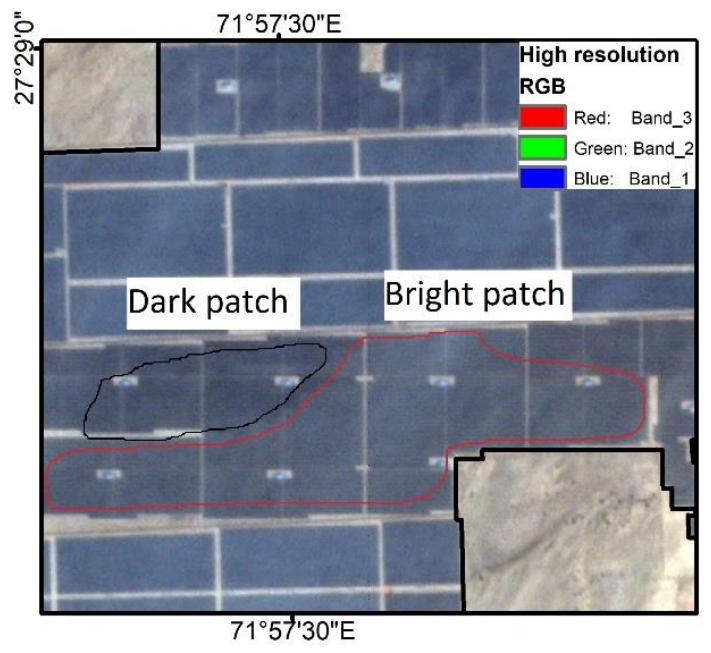

(a)Planet RGB composite (31st January 2018)

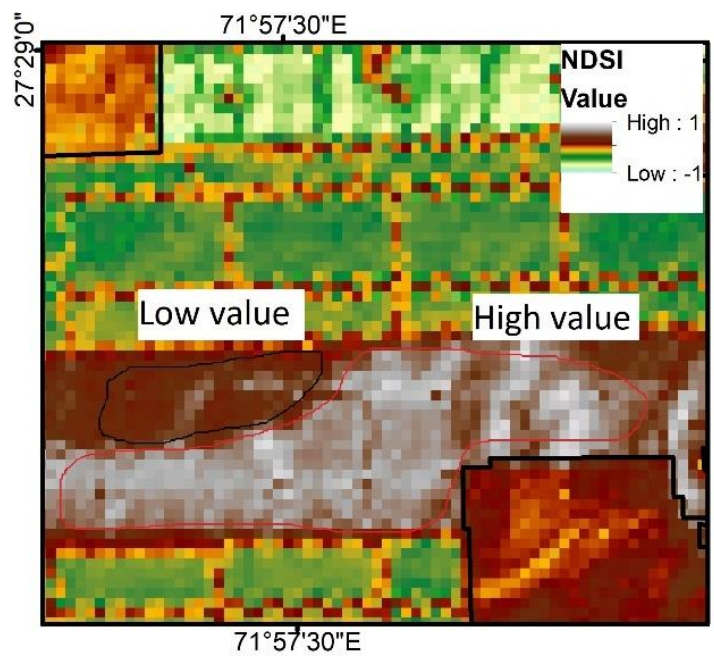

(b)L8 NDSI (31st January 2018)

Figure 13. Cont. 


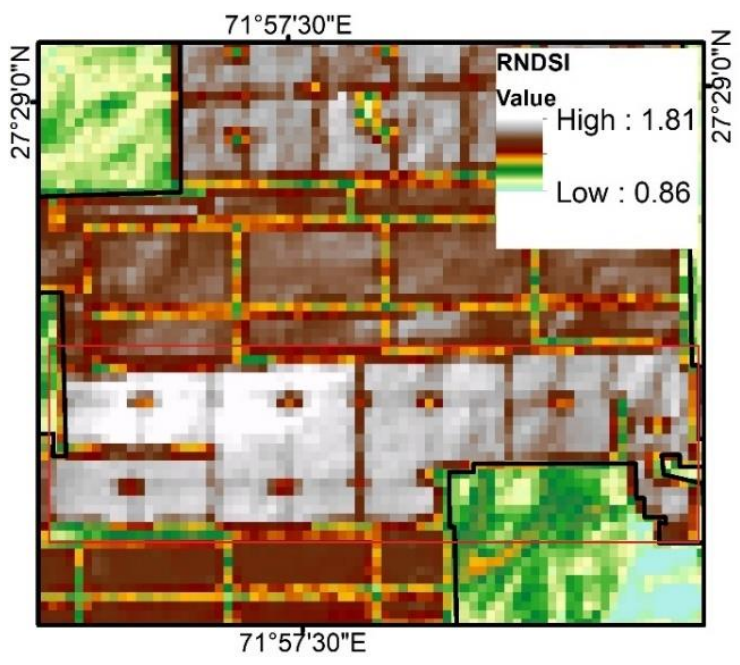

(c)L8 RNDSI (31st January 2018)

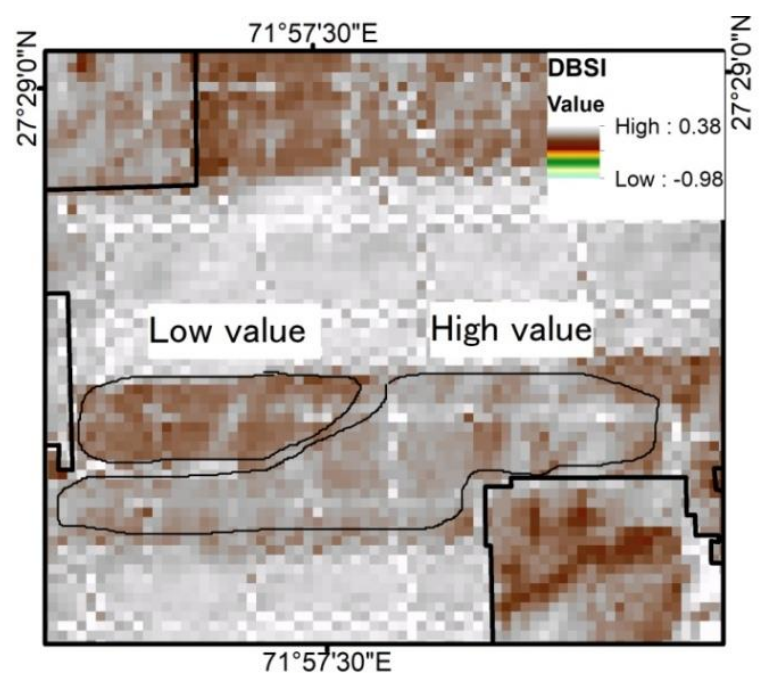

(d)L8 DBSI (31st January 2018)

Figure 13. Comparison of (b) NDSI, (c) RNDSI and (d) DBSI with (a) high-resolution red, green, blue (RGB) PlanetScope data. The bright patches on panels created by sand deposition are highlighted by high value on NDSI, RNDSI and DBSI results.

Figure 14 shows the spectral reflectance graph of the photovoltaic solar panels in different soiling conditions. As displayed in Figure 14a, the cleaner PV solar panels have a low reflectance value of 0.17 and 0.16 in the NIR and SWIR-2 bands, respectively. On the other hand, Figure $14 \mathrm{~b}$ shows that dusty solar panels with dark patches have higher reflectance values of 0.18 and 0.23 in the NIR and SWIR-2 bands, respectively. Figure 14c shows the spectral reflectance of dusty solar panels with a bright patch. It also shows a high reflectance at the bright patch with values of 0.21 and 0.30 in the NIR and SWIR-2 bands, respectively. It can be seen from Figure 14b,c that the dark patch and bright patch have a difference in their reflectance patterns. In the dark patch, NIR and SWIR-2 reflectance values are relatively low compared to the bright patch. In the case of sand, the spectral reflectance is high in NIR and SWIR-2 wavelengths [50]. Figure 14c indicates that the bright patch has high reflectance values in NIR and SWIR-2 compared to the dark patch. This implies that the bright patch is formed by a high amount of sand deposition which has a high reflectance in NIR and SWIR-2 bands. NDSI and DBSI were able to detect this sensitive difference on the panel surface as compared to RNDSI values. Therefore, NDSI and DBSI proved to be more accurate methods to detect sand deposition on solar panels.

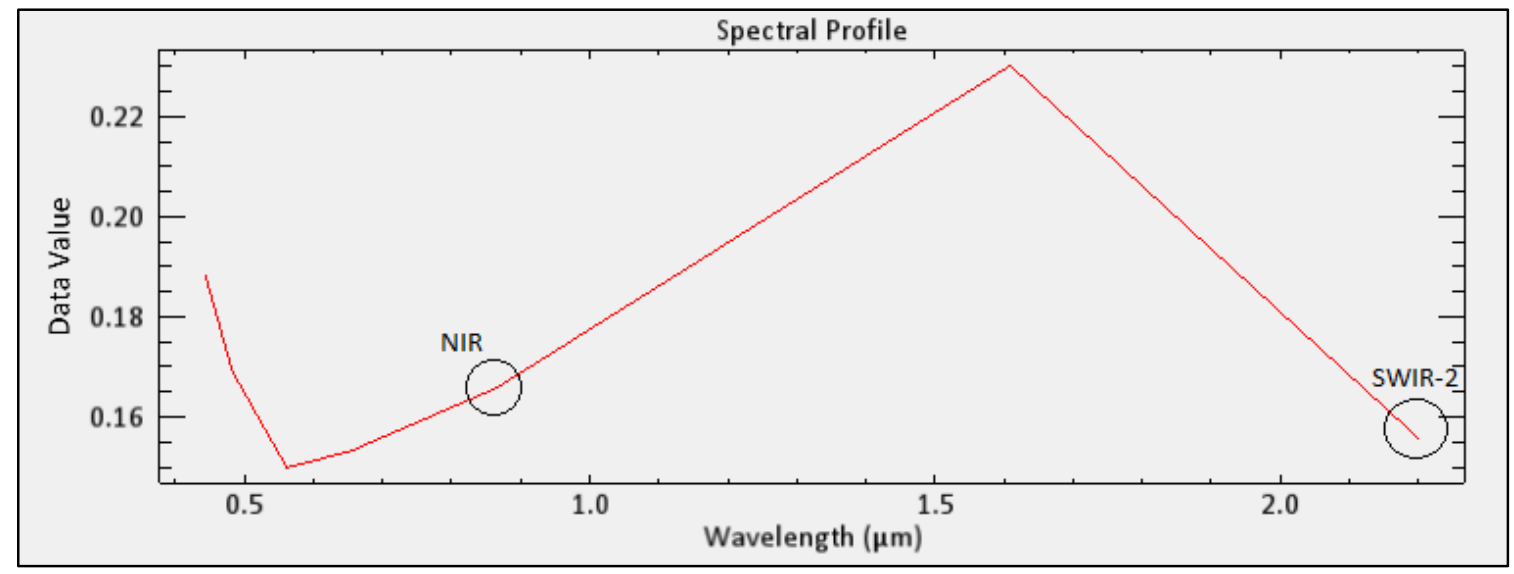

(a) Spectral reflectance of clean solar panels.

Figure 14. Cont. 


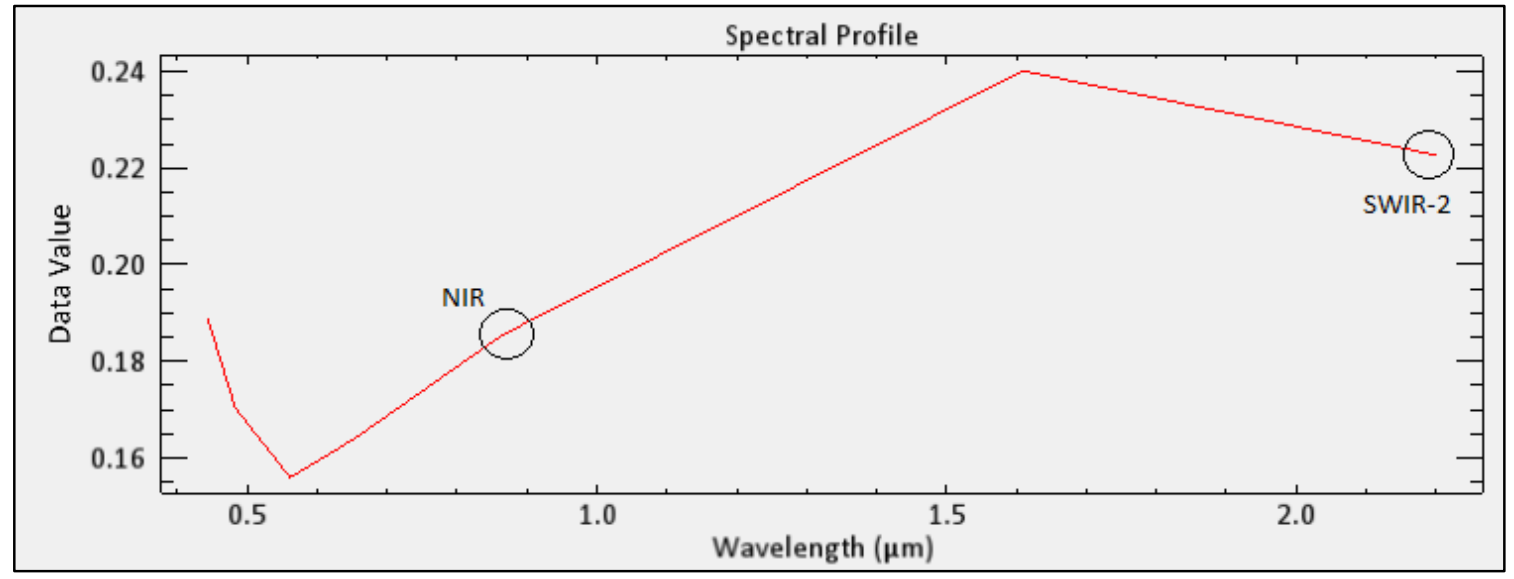

(b) Spectral reflectance of dusty solar panels having a dark patch.

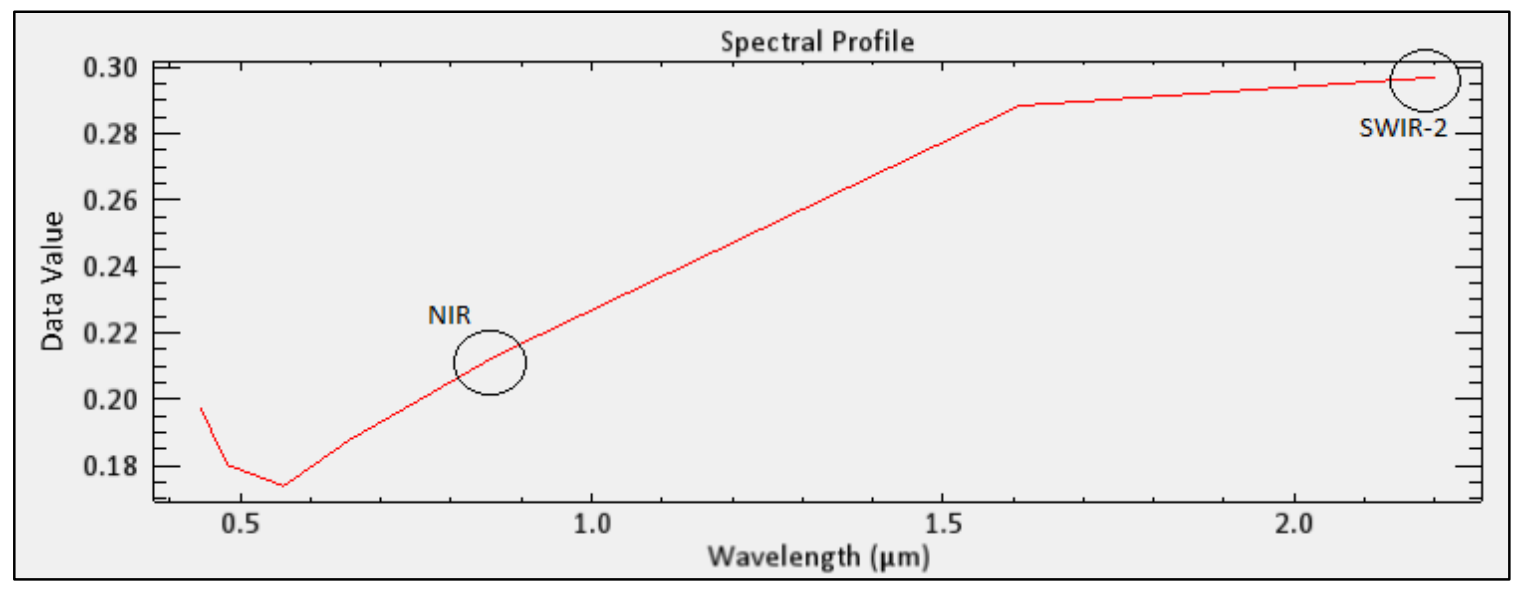

(c) Spectral reflectance of dusty solar panels having the bright patch

Figure 14. Spectral reflectance of (a) clean panels, (b) dusty panels with dark patch and (c) dusty panels with bright patch. Circle highlights the differences in reflectance of near-infrared and short-wave infrared -2 wavelength.

\subsection{Accuracy Assessment}

We also quantified the performance of NDSI, RNDSI, and DBSI against the LST value derived from the Landsat thermal bands. For this, we selected 100 random samples within the solar panel boundaries and extracted the pixel values of NDSI, DBSI, RNDSI, and LST. Later, a threshold value of $40^{\circ}$ Celsius was applied (based on observed changes) to the LST data for representing the change $\left(\geq 40^{\circ} \mathrm{C}\right.$ ) or nonchange $\left(<40^{\circ} \mathrm{C}\right)$ pixels in temperature. Then the performance was evaluated based on various matrices including accuracy, kappa statistics, true positive (TP) and false positive (FP) rates, and the area under receiver operating characteristics curve function (AUC). The results show that DBSI alone can detect the change in temperature with an accuracy of $76 \%$, as displayed in Table 3 . Table 3 also shows that the combination of input data such as DBSI together with NDSI increases the performance of detection significantly, producing an accuracy of $80 \%$. 
Table 3. Performance evaluation metrics of various indices (DBSI, NDSI, and RNDSI) against the land surface temperature derived from Landsat OLI images.

\begin{tabular}{|c|c|c|c|c|c|c|}
\hline \multirow{2}{*}{ Index } & \multirow{2}{*}{ Accuracy } & \multirow{2}{*}{ Kappa } & \multicolumn{2}{|c|}{ Weighted } & \multirow{2}{*}{ AUC } & \multirow{2}{*}{ MCC } \\
\hline & & & TP Rate & FP Rate & & \\
\hline DBSI & $76 \%$ & 0.45 & 0.76 & 0.33 & 0.69 & 0.42 \\
\hline NDSI & $67 \%$ & 0.28 & 0.67 & 0.38 & 0.7 & 0.28 \\
\hline RNDSI & $61 \%$ & 0.14 & 0.61 & 0.46 & 0.65 & 0.15 \\
\hline DBSI+NDSI & $80 \%$ & 0.56 & 0.8 & 0.25 & 0.8 & 0.56 \\
\hline DBSI+RNDSI & $74 \%$ & 0.44 & 0.7 & 0.29 & 0.79 & 0.44 \\
\hline NDSI+RNDSI & $72 \%$ & 0.38 & 0.72 & 0.34 & 0.79 & 0.38 \\
\hline DBSI+NDSI+RNDSI & $79 \%$ & 0.54 & 0.79 & 0.24 & 0.85 & 0.54 \\
\hline
\end{tabular}

Similarly, we quantified the performances of the three indices against PlanetScope data. In this case, we selected 100 points within the solar panel boundaries of four plots and compared them with the observed data points from PlanetScope images. The evaluated performance based on the kappa values and accuracy matrix is shown in Table 4. The DBSI showed the highest accuracy of $89 \%(0.77 \mathrm{kappa})$ among the three indices shown in Table 4.

Table 4. Performance evaluation metrics of various indices (DBSI, NDSI, and RNDSI) in detecting the soiled and clean pixel as verified from PlanetScope Images.

\begin{tabular}{ccccccc}
\hline \multirow{2}{*}{ Index } & \multirow{2}{*}{ Accuracy } & \multirow{2}{*}{ Kappa } & \multicolumn{2}{c}{ Weighted } & \multirow{2}{*}{ TP Rate } & FP Rate \\
& & & AUC & \multirow{2}{*}{ MCC } \\
\hline DBSI & $89.6 \%$ & 0.77 & 0.89 & 0.12 & 0.86 & 0.77 \\
NDSI & $87.9 \%$ & 0.73 & 0.87 & 0.15 & 0.88 & 0.73 \\
RNDSI & $86.2 \%$ & 0.70 & 0.86 & 0.14 & 0.88 & 0.70 \\
\hline
\end{tabular}

\section{Discussion}

The spectral indices approach has been widely used to highlight various land cover types. Various indices have been developed for vegetation and water in past decades. However, few indices have been developed to monitor sand directly. The main reason is the complexity of sand properties and their spectral reflectance. The spectral reflectance varies with the moisture, texture, and other physical properties. From the results, it can be noticed that soiling can be detected by a customized interpretation of indices by visual cross-verifications. Al-Quraishi [27] monitored the sand dune accumulations and encroachment using NDSI with an accuracy of $90.8 \%$ in Iraq. The NDSI based method provided impressive results for mapping and monitoring sand dunes [27]. Its effective monitoring of sand dunes is useful for the selection of suitable control procedures and the prevention of further expansion. Similarly, empirically derived RNDSI highlights soil information and suppresses the noises (e.g., brightness factor caused by built-up). It is an effective technique in separating soil form the panel surfaces. RNDSI has a limitation when it comes to separating moist soil from dark impervious surfaces [26] and as RNDSI calculation is based on tasseled cap transformation of a particular image, it might cause less robust application in detecting soiling. Since the study area is covered with arid soil, it can be effectively identified on dark panel surfaces. Moreover, such arid soils are very dry, so the use of DBSI was helpful to particularly focus on bare soil.

A comparative analysis was performed between NDSI, DBSI and RNDSI only since they belong to the same data lineage. Data taken at the same time is imperative for comparative purposes. Moreover, Landsat 8 images were considered for this analysis because of the availability of thermal bands which were further required for LST based validation. The DBSI index generated from a relatively high-resolution Sentinel-2 data is found to be an effective technique and a viable alternative, and it could be used to highlight the high soiling area by applying an arbitrary threshold after visual verification [25]. The images acquired by high-resolution PlanetScope provides a true color composite 
view of the PV panels that helps us in detecting the substantial soiling in the panels. Both qualitative and quantitative approaches were used to compare the accuracy of indices to evaluate their ability to detect minute differences in soiling on the PV panels.

The field survey also revealed important information that supports the findings of this study. As per the standard operating manual of the SECI, the solar plants in Bhadla is being divided into different sections consisting of 400 to 800 panels. Our interviews with the project managers and solar plant operators of different solar units of the four parks in Bhadla concluded that the solar farms here experience a high soiling period starting from January till May. The atmospheric temperature during daytime rises above $50^{\circ} \mathrm{C}$ from March to May. Frequent dust storm events are also noticed during this period which causes more frequent soiling. Sudden drops in soiling were also reported from July until December. Manual cleaning of each section of some plants with water is conducted in 10 to 15-day cycles, while others with Ecoppia E4 robots perform cleaning operations daily. Figure 15a,b shows the photographs captured during the field survey for the cleaning of PV panels using water spray systems, and Ecoppia E4 robot systems mounted on the PV panels, respectively.

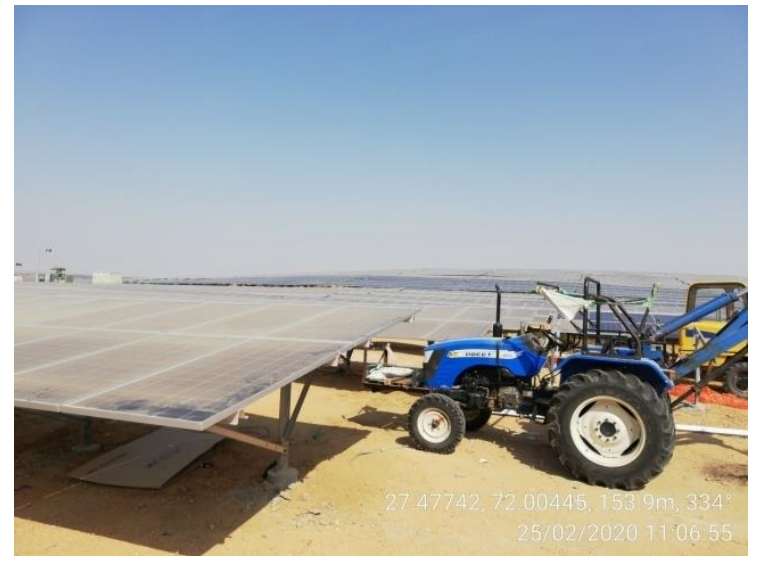

(a) Manual cleaning

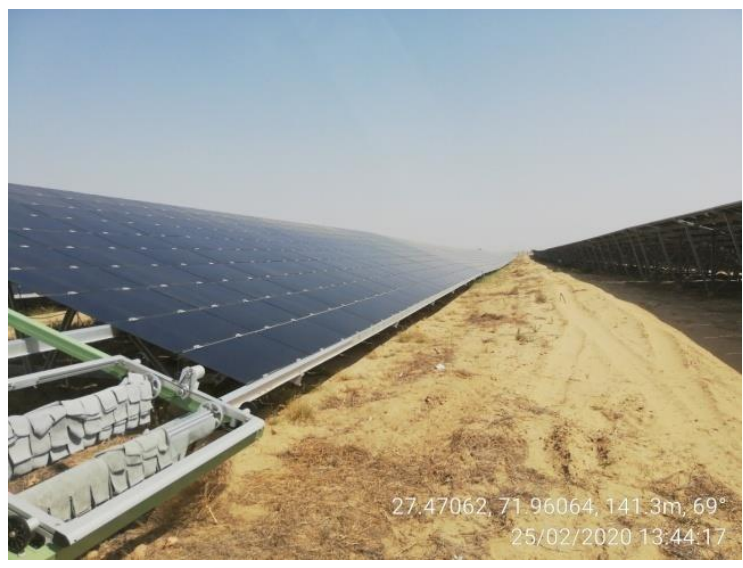

(b) Robotic cleaning

Figure 15. (a) A tractor vehicle mounted with a water spray system used for manual cleaning; (b) Ecoppia E4 robot mounted on one of the panel rows.

From a future perspective, the accuracy of the soil detection can be improved by using high-resolution satellite data more precisely, as noticed in the case of DBSI from Sentinel-2 $10 \mathrm{~m}$ images. However, high temporal resolution data is also required to distinguish the soiling phenomenon more frequently. Thus, a viable alternative will be the use of unmanned aerial vehicles (UAVs) technology, that provide high spatial and temporal resolution data. However, more monetary and technical investments are required to conduct such studies. Recently, with technical advancement in drone and imaging engineering, both thermal and optical cameras can be mounted on a UAV, thus generating results with higher precision. Further research is needed to improve the threshold optimization for DBSI based detection by conducting studies in different regions with varying meteorological and landscape conditions.

\section{Conclusions}

This study demonstrates the use of optical satellite data to monitor the soiling phenomenon on solar panels. The GEE tool is effectively used for rapid computation, processing, generation, and extraction of satellite data with semiautomated processing to detect soiling on PV panels cost-effectively. The frequent generation of results for a longer time frame was necessary for this study. This was achieved easily because of automated processes performed on the GEE platform. The NDSI, RNDSI and DBSI were used to detect the soiling phenomenon at the temporal scale. All of these indices could detect soiling on solar panels of PV solar farms. Moreover, a comparison of results with the LST and 
high-resolution images with the sand and soil indices could qualitatively verify the results. The time series analysis of various indices revealed the amount of sand depositions right from the start of the project. Based on the accuracy assessment conducted on the three indices used in this study, DBSI proved to be the most accurate in identifying the soiled areas. The soiling was more frequent from January to May and less frequent from July to August. This change is mainly because of change in the weather conditions, as precipitation in the July and August months is significantly different when compared to the other months.

The monitoring of soiling on existing solar farms can discern information about soiling periods and intensity. This information can be useful to adopt a proper cleaning mechanism at required intervals. The approach used in this study is efficient and cost-effective. The Indian solar companies currently adopt a fixed schedule for cleaning which is not realistic. The methods discussed in this study could be used as an alternative source of information and provide a profound view of the field survey. However, these approaches have some limitations, and further development of the detection techniques is necessary.

Author Contributions: Conceptualization, H.S. and R.A.; methodology, H.S., R.A., A.P.Y., A.K.; software, H.S., A.G., A.A.R. and R.A.; formal analysis, H.S., V.S., J.D. and R.A.; investigation, H.S., C.K.S., O.T., A.K. and R.A.; writing-original draft preparation, H.S., A.P.Y., A.K. and R.A.; writing-review and editing, H.S., R.A., D.S., A.G., A.P.Y., J.D., A.R., G.M., S.K.C., V.S., C.K.S., O.T., and A.K. All authors have read and agreed to the published version of the manuscript.

Funding: This research received no external funding.

Acknowledgments: Authors would like to thank Hokkaido University and Japan Student Services Organization (JASSO) for providing fellowship. The authors also express gratitude towards Officers and Staff of the Rajasthan Renewable Energy Corporation Limited (RRECL) for granting permission to conduct the field survey in Bhadla solar farm. Furthermore, the authors are thankful to Planet lab, Copernicus Sentinel-2 data hub and the United States Geological Survey (USGS) for providing satellite data. We also acknowledge the support of Minh, Stanley, Mustafizur, Manish Soongra and Anil and appreciate the contribution made by the anonymous reviewers.

Conflicts of Interest: The authors declare no conflict of interest.

\section{References}

1. Avtar, R.; Tripathi, S.; Aggarwal, A.K.; Kumar, P. Population-Urbanization-Energy Nexus: A Review. Resources 2019, 8, 136. [CrossRef]

2. Avtar, R.; Sahu, N.; Aggarwal, A.K.; Chakraborty, S.; Kharrazi, A.; Yunus, A.P.; Dou, J.; Kurniawan, T.A. Kurniawan Exploring Renewable Energy Resources Using Remote Sensing and GIS-A Review. Resources 2019, 8, 149. [CrossRef]

3. Avtar, R.; Tripathi, S.; Aggarwal, A.K. Assessment of Energy-Population-Urbanization Nexus with Changing Energy Industry Scenario in India. Land 2019, 8, 124. [CrossRef]

4. Raturi, A.K. Asia and the Pacific Renewable Energy Status Report; REN21: Suva, Fiji, 2019.

5. Devabhaktuni, V.; Alam, M.; Shekara Sreenadh Reddy Depuru, S.; Green, R.C.; Nims, D.; Near, C. Solar energy: Trends and enabling technologies. Renew. Sustain. Energy Rev. 2013, 19, 555-564. [CrossRef]

6. Sahu, B.K. A study on global solar PV energy developments and policies with special focus on the top ten solar PV power producing countries. Renew. Sustain. Energy Rev. 2015, 43, 621-634. [CrossRef]

7. PV Solar Power around the World. Available online: https://en.wikipedia.org/wiki/Solar_power_by_country (accessed on 5 April 2019).

8. Yap, W.K.; Galet, R.; Yeo, K.C. Quantitative analysis of dust and soiling on solar pv panels in the tropics utilizing image-processing methods. In Proceedings of the 2015 Asia-Pacific Solar Research Conference, Brisbane, Australia, 9 December 2015.

9. Wilson, N.R.; Norman, L.M.; Villarreal, M.; Gass, L.; Tiller, R.; Salywon, A. Comparison of remote sensing indices for monitoring of desert cienegas. Arid Land Res. Manag. 2016, 30, 460-478. [CrossRef]

10. Li, D. Using GIS and Remote Sensing Techniques for Solar Panel Installation Site Selection. Master's Thesis, University of Waterloo, Waterloo, ON, Canada, 2013.

11. Bergin, M.H.; Ghoroi, C.; Dixit, D.; Schauer, J.J.; Shindell, D.T. Large reductions in solar energy production due to dust and particulate air pollution. Environ. Sci. Technol. Lett. 2017, 4, 339-344. [CrossRef] 
12. Avtar, R.; Aggarwal, R.; Kharrazi, A.; Kumar, P.; Kurniawan, T.A. Utilizing geospatial information to implement SDGs and monitor their Progress. Environ. Monit. Assess. 2020, 192, 35. [CrossRef]

13. Avtar, R.; Kumar, P.; Oono, A.; Saraswat, C.; Dorji, S.; Hlaing, Z. Potential application of remote sensing in monitoring ecosystem services of forests, mangroves and urban areas. Geocarto Int. 2017, 32, 874-885. [CrossRef]

14. Saidan, M.; Albaali, A.G.; Alasis, E.; Kaldellis, J.K. Experimental study on the effect of dust deposition on solar photovoltaic panels in desert environment. Renew. Energy 2016, 92, 499-505. [CrossRef]

15. Salim, A.; Huraib, F.; Eugenio, N. PV power-study of system options and optimization. In Proceedings of the EC photovoltaic Solar Conference, Florence, Italy, 8-9 May 1988; pp. 688-692.

16. Jain, A.; Kapoor, A. Exact analytical solutions of the parameters of real solar cells using Lambert W-function. Sol. Energy Mater. Sol. Cells 2004, 81, 269-277. [CrossRef]

17. Jiang, H.; Lu, L.; Sun, K. Experimental investigation of the impact of airborne dust deposition on the performance of solar photovoltaic (PV) modules. Atmos. Environ. 2011, 45, 4299-4304. [CrossRef]

18. Gupta, J. Wind erosion of soil in drought-prone areas. In Desertification and Its Control in the Thar, Sahara and Sahel Regions; Scientific Publisher: Jodhpur, India, 1993.

19. Schill, C.; Brachmann, S.; Koehl, M. Impact of soiling on IV-curves and efficiency of PV-modules. Sol. Energy 2015, 112, 259-262. [CrossRef]

20. Maghami, M.R.; Hizam, H.; Gomes, C.; Radzi, M.A.; Rezadad, M.I.; Hajighorbani, S. Power loss due to soiling on solar panel: A review. Renew. Sustain. Energy Rev. 2016, 59, 1307-1316. [CrossRef]

21. Zea-Cabrera, E.; Iwasa, Y.; Levin, S.; Rodríguez-Iturbe, I. Tragedy of the commons in plant water use. Water Resour. Res. 2006, 42. [CrossRef]

22. Karnataka: $100 \%$ Water Tariff Hike Ups Production Cost for Heavy Industries. Available online: https://economictimes.indiatimes.com/industry/indl-goods/svs/steel/karnataka-100-water-tariff-hike-ups -production-cost-for-heavy-industries/articleshow/65167007.cms?from=mdr (accessed on 15 April 2019).

23. Avtar, R.; Herath, S.; Saito, O.; Gera, W.; Singh, G.; Mishra, B.; Takeuchi, K. Application of remote sensing techniques toward the role of traditional water bodies with respect to vegetation conditions. Environ. Dev. Sustain. 2014, 16, 995-1011. [CrossRef]

24. Minh, H.V.T.; Avtar, R.; Mohan, G.; Misra, P.; Kurasaki, M. Monitoring and Mapping of Rice Cropping Pattern in Flooding Area in the Vietnamese Mekong Delta Using Sentinel-1A Data: A Case of An Giang Province. IJGI 2019, 8, 211. [CrossRef]

25. Rasul, A.; Balzter, H.; Ibrahim, G.; Hameed, H.; Wheeler, J.; Adamu, B.; Ibrahim, S.; Najmaddin, P. Applying built-up and bare-soil indices from Landsat 8 to cities in dry climates. Land 2018, 7, 81. [CrossRef]

26. Deng, Y.; Wu, C.; Li, M.; Chen, R. RNDSI: A ratio normalized difference soil index for remote sensing of urban/suburban environments. Int. J. Appl. Earth Obs. Geoinf. 2015, 39, 40-48. [CrossRef]

27. Al-Quraishi, A. Sand Dunes Monitoring Using Remote Sensing and GIS Techniques for Some Sites in Iraq; International Society for Optics and Photonics: Sanya, China, 2013.

28. Rudiyanto; Minasny; Shah; Soh; Arif; Setiawan Automated Near-Real-Time Mapping and Monitoring of Rice Extent, Cropping Patterns, and Growth Stages in Southeast Asia Using Sentinel-1 Time Series on a Google Earth Engine Platform. Remote Sens. 2019, 11, 1666. [CrossRef]

29. Bhadla Solar Park, Rajasthan. Available online: https://www.nsenergybusiness.com/projects/bhadla-solar-p ark-rajasthan/ (accessed on 24 April 2019).

30. Pandey, S. Success in Scaling-up Solar Energy in Rajasthan, India. 2013. Available online: http://re.indiaenvironmentportal.org.in/files/file/Success\%20in\%20Scaling-up\%20Solar\%20Energy \%20in\%20Rajasthan,\%20India.pdf (accessed on 5 May 2019).

31. Publications Division. INDIA 2019: A Reference Mannual, 1st ed.; Ministry of Information \& Broadcasting, Government of India: New Delhi, India, 2018; Volume 63.

32. Kar, S.K.; Sharma, A.; Roy, B. Solar energy market developments in India. Renew. Sustain. Energy Rev. 2016, 62, 121-133. [CrossRef]

33. Climate Data. Available online: https://en.climate-data.org/asia/india-129/ (accessed on 3 May 2019).

34. Adani Group. Available online: https://www.areprl.com/solar-resource/\#solarbhadla (accessed on 12 June 2019).

35. Google Earth Engine. Available online: https://earthengine.google.com/ (accessed on 14 April 2019). 
36. GIS Course. Available online: https://www.giscourse.com/ (accessed on 21 April 2019).

37. Márquez, F.P.G.; Ramírez, I.S. Condition monitoring system for solar power plants with radiometric and thermographic sensors embedded in unmanned aerial vehicles. Measurement 2019, 139, 152-162. [CrossRef]

38. Bonafoni, S. Downscaling of Landsat and MODIS land surface temperature over the heterogeneous urban area of Milan. IEEE J. Sel. Top. Appl. Earth Obs. Remote Sens. 2016, 9, 2019-2027. [CrossRef]

39. Saradjian, M.R.; Jouybari-Moghaddam, Y. Land Surface Emissivity and temperature retrieval from Landsat- 8 satellite data using Support Vector Regression and weighted least squares approach. Remote Sens. Lett. 2019, 10, 439-448. [CrossRef]

40. Hofierka, J.; Gallay, M.; Onačillová, K.; Hofierka, J., Jr. Physically-based land surface temperature modeling in urban areas using a 3-D city model and multispectral satellite data. Urban Clim. 2020, 31, 100566. [CrossRef]

41. Rahman, M.; Avtar, R.; Yunus, A.P.; Dou, J.; Misra, P.; Takeuchi, W.; Sahu, N.; Kumar, P.; Johnson, B.A.; Dasgupta, R. Monitoring Effect of Spatial Growth on Land Surface Temperature in Dhaka. Remote Sens. 2020, 12, 1191. [CrossRef]

42. Wang, F.; Qin, Z.; Song, C.; Tu, L.; Karnieli, A.; Zhao, S. An Improved Mono-Window Algorithm for Land Surface Temperature Retrieval from Landsat 8 Thermal Infrared Sensor Data. Remote Sens. 2015, 7, 4268-4289. [CrossRef]

43. Israel's Ecoppia To Deploy 2000 E4 Solar Panel Cleaning Robots for SB Energy's Installations in Bhadla Solar Park. Available online: http://taiyangnews.info/business/ecoppia-secures-580-mw-order-for-bhadla-solarpark/ (accessed on 24 April 2019).

44. Patil, P.; Bagi, J.; Wagh, M. A review on cleaning mechanism of solar photovoltaic panel. In Proceedings of the 2017 International Conference on Energy, Communication, Data Analytics and Soft Computing (ICECDS), Chennai, India, 1-2 August 2017; pp. 250-256.

45. Ecoppia Expands Bhadla Park Cloud-Based Robotic Cleaning Footprint with Additional 580MWp. Available online: https://www.ecoppia.com/press-releases/ecoppia-expands-bhadla-park-cloud-based-robot ic-cleaning-footprint-with-additional-580mwp/ (accessed on 15 May 2019).

46. PV Solar Panel Field Inspection with UgCS. 2013. Available online: https://www.ugcs.com/solar-panel-inspe ction-with-ugcs (accessed on 25 June 2019).

47. Kidron, G.; Yair, A. Rainfall-runoff relationship over encrusted dune surfaces, Nizzana, Western Negev, Israel. Earth Surf. Process. Landf. J. Br. Geomorphol. Group 1997, 22, 1169-1184. [CrossRef]

48. Tsoar, H. Sand dunes mobility and stability in relation to climate. Phys. A Stat. Mech. Appl. 2005, 357, 50-56. [CrossRef]

49. Van Dijk, P.; Stroosnijder, L.; De Lima, J. The influence of rainfall on transport of beach sand by wind. Earth Surf. Process. Landf. 1996, 21, 341-352. [CrossRef]

50. O'Neill, A.L. Reflectance spectra of microphytic soil crusts in semi-arid Australia. Int. J. Remote Sens. 1994, 15, 675-681. [CrossRef]

(C) 2020 by the authors. Licensee MDPI, Basel, Switzerland. This article is an open access article distributed under the terms and conditions of the Creative Commons Attribution (CC BY) license (http://creativecommons.org/licenses/by/4.0/). 